\title{
FRACTURE ASSESSMENTS WITH ELASTIC FOLLOW-UP FOR COMBINED PRIMARY AND SECONDARY LOADINGS PART 2: NUMERICAL VALIDATION
}

DOI:

10.1016/j.engfracmech.2019.106796

\section{Document Version}

Accepted author manuscript

Link to publication record in Manchester Research Explorer

Citation for published version (APA):

Lee, H-J., Kim, Y-J., Ainsworth, R., \& Oh, C-Y. (2019). FRACTURE ASSESSMENTS WITH ELASTIC FOLLOWUP FOR COMBINED PRIMARY AND SECONDARY LOADINGS PART 2: NUMERICAL VALIDATION.

Engineering Fracture Mechanics. https://doi.org/10.1016/j.engfracmech.2019.106796

Published in:

Engineering Fracture Mechanics

\section{Citing this paper}

Please note that where the full-text provided on Manchester Research Explorer is the Author Accepted Manuscript or Proof version this may differ from the final Published version. If citing, it is advised that you check and use the publisher's definitive version.

\section{General rights}

Copyright and moral rights for the publications made accessible in the Research Explorer are retained by the authors and/or other copyright owners and it is a condition of accessing publications that users recognise and abide by the legal requirements associated with these rights.

\section{Takedown policy}

If you believe that this document breaches copyright please refer to the University of Manchester's Takedown Procedures [http://man.ac.uk/04Y6Bo] or contact uml.scholarlycommunications@manchester.ac.uk providing relevant details, so we can investigate your claim.

\section{OPEN ACCESS}




\section{FRACTURE ASSESSMENTS WITH ELASTIC FOLLOW-UP FOR COMBINED PRIMARY AND SECONDARY LOADINGS PART 2: NUMERICAL VALIDATION}

Hyun-Jae Lee ${ }^{1}$, Yun-Jae Kim ${ }^{1}$, R A Ainsworth ${ }^{2}$, Chang-Young $\mathrm{Oh}^{3}$

${ }^{1}$ Department of Mechanical Engineering, Korea University, Anam-Dong, Seongbuk-Gu, Seoul 02841, Republic of Korea

${ }^{2}$ School of Mechanical, Aerospace \& Civil Engineering, The University of Manchester, Manchester M13 9PL, UK

${ }^{3}$ Joining Technology Department, Korea Institute of Materials Science, Sangnam-Dong, Seongsan-Gu, Changwon 51508, Republic of Korea

${ }^{1}$ Corresponding author, email: kimy0308@korea.ac.kr (Yun-Jae Kim)

Manuscript for Submission to

Engineering Fracture Mechanics

Submission Date: July 2019

$1^{\text {st }}$ Revision Date: October 2019 


\begin{abstract}
This paper presents comparisons of finite element (FE) results with the $J$ estimation equations proposed in Part 1 for treating fracture under combined primary and secondary loadings. The FE analyses are performed for a pipe with a circumferential internal surface crack subjected to axial tension combined with thermal loading. The crack depth and length, the relative magnitude of axial tension and thermal loadings, loading sequence and material properties are systematically varied. Based on the FE results, the applicability of the proposed equations in Part 1 is discussed and new estimation equations obtained by modifying the existing equations are proposed and validated.
\end{abstract}

Keywords: Secondary loading, failure assessment diagram, elastic follow-up

\title{
Nomenclature
}

a crack size

E Young's modulus

f failure assessment curve (FAC) in R6

$\mathrm{h}_{1} \quad$ function in Eq. (7)

J J-integral

$\mathrm{J}^{s}, \mathrm{~J}_{\mathrm{e}}^{\mathrm{s}} \mathrm{J}$ value for secondary loading acting alone, and its elastically calculated value

$\mathrm{J}^{\mathrm{p}}, \mathrm{J}_{\mathrm{e}}^{\mathrm{p}} \mathrm{J}$ value for primary loading acting alone, and its elastically calculated value

$\mathrm{J}^{\mathrm{p}+\mathrm{s}} \quad \mathrm{J}$ value for combined primary and secondary loading

$\mathrm{K}_{\mathrm{I}}^{\mathrm{p}}, \mathrm{K}_{\mathrm{I}}^{\mathrm{s}}$ elastic stress intensity factor for primary and secondary loading, respectively

$\mathrm{L}_{r} \quad$ proximity parameter to plastic collapse

$\mathrm{n} \quad$ stress exponent for power-law plasticity

$\mathrm{P} \quad$ generalized primary load

$\mathrm{P}_{\mathrm{L}} \quad$ Limit load

r mean pipe radius

t thickness

$\mathrm{V}$ multiplying factor to incorporate secondary stress effects on $\mathrm{J}$

$\mathrm{V}^{(\mathrm{n})} \quad$ various estimates of $\mathrm{V}(\mathrm{n}=1-6)$ in Eqs. $(1-3,7,16-17)$

$\mathrm{V}_{\mathrm{o}} \quad$ value of $\mathrm{V}$ for the secondary stress acting alone

$\mathrm{x} \quad$ variable

$\mathrm{Z}$ elastic follow-up factor

$\mathrm{Z}^{\mathrm{s}} \quad$ elastic follow-up factor for secondary loading alone

$\alpha \quad$ multiplying constant in Ramberg-Osgood relationship of Eq. (8)

$\beta \quad$ normalised relative elastic magnitude of secondary loading, Eq. (5)

$\Delta \mathrm{T}_{\max }$ the maximum value of temperature gradient

$\varepsilon \quad$ total strain

$\varepsilon_{\text {ref }}^{\mathrm{s}} \quad$ strain at stress $\sigma_{\text {ref }}^{\mathrm{s}}$ 
$\varepsilon_{\text {ref }}^{\mathrm{sel}} \quad$ elastic strain at stress $\sigma_{\text {ref }}^{\mathrm{sel}}$

$\theta$ half circumferential angle of a circumferential crack

$v \quad$ Poisson's ratio

$\sigma \quad$ stress

$\sigma_{\text {ref }}^{\mathrm{s}} \quad$ reference stress for secondary loading

$\sigma_{\text {ref }}^{\text {s,el }} \quad$ elastic estimate of secondary reference stress

$\sigma_{\mathrm{y}} \quad$ yield strength 


\section{INTRODUCTION}

For linear elastic response, the total stress intensity factor under combined primary and secondary loading is simply calculated by linearly adding the values for each loading. However, the contribution of secondary stresses in post-yield fracture is more complex and fitness-for-service procedures such as R6 [1] provide the V-factor approach to address the varying effects of plasticity on the contribution of secondary loads to the total value of J. Recent studies [2-4] show that the values of V depend on the degree of elastic follow-up, described by an elastic follow-up factor $Z$. While accurate estimates of $\mathrm{V}$, and hence $\mathrm{J}$, are available when there is no follow-up $(\mathrm{Z}=1)$ and when secondary loads act as primary $(Z \rightarrow \infty)$ a general treatment for estimating $\mathrm{J}$ or $\mathrm{V}$ for any degree of elastic follow-up is not yet clear.

In Part 1 [5], guidance on estimating the elastic follow-up factor $Z$ and associated $\mathrm{J}$ estimates for cracked components under combined primary and secondary loadings is given. A simplified approach for estimating $\mathrm{Z}$ is also proposed, and several $\mathrm{V}$ estimation equations are provided based on R6 [1] and other papers [3, 5-6]. Some of these equations are summarised here in Section 2 for completeness.

It is known that the elastic-plastic value of $\mathrm{J}$ can depend on the load order (for instance, whether the primary load is applied first followed by the secondary load, or vice-versa). The equations presented in Part 1 and summarised in Section 2 do not depend on load order and the applicability of the equations under different load orders is investigated in this paper.

Furthermore, the equations depend on the degree of elastic follow-up, Z, and require the value of $Z$ to be known. A method for estimating $Z$ is given in [5], based on analysis for secondary loads acting alone. However, for small secondary loads such that response is essentially elastic, it is not possible, nor necessary, to define $Z$ for the secondary loads acting alone. However, under combined loading a value of $Z$ is required to describe relaxation of the secondary loads, even when these are small, and hence another indicator of the degree of elastic follow-up is needed. This is examined in this paper.

This paper has two main objectives. The first is FE validation of the proposed $\mathrm{V}$ estimation equations in Part 1, including validation that they conservatively apply irrespective of the load order. The second objective is to investigate $\mathrm{J}$ estimation equations for cases of small, essentially elastic, secondary loading. For the FE analyses, a pipe with a circumferential internal surface crack subject to axial tension and thermal loading is considered. Relevant parameters (crack depth and length, the relative magnitude of thermal loading, loading sequence and material) are systematically varied. Section 3 describes the FE analysis procedure, including the methods of calculating $\mathrm{Z}$ and $\mathrm{V}$ from the FE results. The FE results are then given in 
Sections 4 and 5, where comparisons with estimation equations are made. The presented work is concluded in Section 5.

\section{SUMMARY OF EQUATIONS FOR ESTIMATING J}

In R6 [1], three $\mathrm{V}$ estimation equations are currently provided depending on the magnitude of the elastic follow-up factor; for $Z=1, Z \leq 3$ and $Z>3$.

$$
\begin{aligned}
& \frac{\mathrm{V}^{(1)}}{\mathrm{V}_{\mathrm{o}}}=\mathrm{f}\left(\mathrm{L}_{\mathrm{r}}\right), \mathrm{Z}=1 \\
& \frac{\mathrm{V}^{(2)}}{\mathrm{V}_{\mathrm{o}}}=\mathrm{f}\left(\mathrm{L}_{\mathrm{r}}\right)+0.42 \mathrm{~L}_{\mathrm{r}}\left(0.72+\mathrm{L}_{\mathrm{r}}\right)\left[\mathrm{f}\left(\mathrm{L}_{\mathrm{r}}\right)\right]^{2}, \mathrm{Z} \leq 3 \\
& \frac{\mathrm{V}^{(3)}}{\mathrm{V}_{\mathrm{o}}}=\mathrm{f}\left(\mathrm{L}_{\mathrm{r}}\right)+\frac{3}{4} \frac{\mathrm{Z}-1}{\mathrm{Z}} \mathrm{L}_{\mathrm{r}}\left(\beta+\mathrm{L}_{\mathrm{r}}\right) \frac{\left[\mathrm{f}\left(\mathrm{L}_{\mathrm{r}}\right)\right]^{2}}{\mathrm{~V}_{\mathrm{o}}}, \mathrm{Z}>3, \mathrm{~L}_{\mathrm{r}}+\beta \leq 0.7
\end{aligned}
$$

where $L_{r}, \beta$ and $V_{o}$ denote the ratio of primary load to limit load, the normalised elastic magnitude of secondary load and the values of $\mathrm{V}$ for the secondary stress acting alone, respectively. These are defined by

$$
\begin{aligned}
& \mathrm{L}_{\mathrm{r}}=\mathrm{P} / \mathrm{P}_{\mathrm{L}} \\
& \beta=\frac{\mathrm{K}_{\mathrm{I}}^{\mathrm{s}}}{\mathrm{K}_{\mathrm{I}}^{\mathrm{p}} / \mathrm{L}_{\mathrm{r}}} \\
& \mathrm{V}_{\mathrm{o}}=\sqrt{\mathrm{J}^{\mathrm{s}} / \mathrm{J}_{\mathrm{e}}^{\mathrm{s}}}
\end{aligned}
$$

where $\mathrm{P}$ and $\mathrm{P}_{\mathrm{L}}$ are the applied primary load and the limit load, respectively. $\mathrm{K}_{\mathrm{I}}^{\mathrm{p}}$ and $\mathrm{K}_{\mathrm{I}}^{\mathrm{s}}$ are the stress intensity factors for the primary and secondary loads, and $\mathrm{J}^{\mathrm{s}}$ and $\mathrm{J}_{\mathrm{e}}^{\mathrm{s}}$ denote the value of $\mathbf{J}$ and the elastically calculated value of $\mathbf{J}$ for the secondary loading acting alone, respectively. In Eqs. (1)-(3), $f\left(\mathrm{~L}_{r}\right)$ is the R6 failure assessment curve [1].

Note that Eq. (3) has a limited application range in Lr. Accordingly, more general equations for large $\mathrm{Z}$ have been proposed in Part 1 [5]. One of these is

$$
\begin{aligned}
& \frac{V^{(4)}}{V_{o}}=f\left(L_{r}\right)+\frac{Z-2}{Z} h_{1}\left(L_{r}, \beta\right), \text { for large } Z \\
& h_{1}\left(L_{r}, \beta\right)=\frac{\left(L_{r}+\beta\right) f\left(L_{r}\right) f(\beta)}{\beta f\left(L_{r}+\beta\right)}-\frac{L_{r} f(\beta)}{\beta}-f\left(L_{r}\right)
\end{aligned}
$$

It should be noted that $\mathrm{V}^{(4)}$ has no limitation of the magnitude of combined loadings, compared with other $\mathrm{V}$ estimates for large $\mathrm{Z}$ suggested in Part 1 [5] including the 
equations currently given in R6 (see Eqs. (19)-(22) in [5]). Thus implies that $\mathrm{V}^{(3)}$ can be replaced by $\mathrm{V}^{(4)}$.

\section{FINITE ELEMENT ANALYSIS}

\subsection{Geometry}

In this work, a circumferentially cracked pipe with $\mathrm{r} / \mathrm{t}=5,10$ and 20 (the mean radius $r$ and the pipe thickness $t$ ) is considered. Figure 1 shows a circumferential partthrough constant-depth internal surface crack characterized by the relative crack length, $\theta / \pi$, and depth, a/t. The following values of $\theta / \pi$ and $a / t$ are considered: $\theta / \pi=0.0625,0.125$ and 0.25 ; and $\mathrm{a} / \mathrm{t}=0.3,0.5$ and 0.7 .

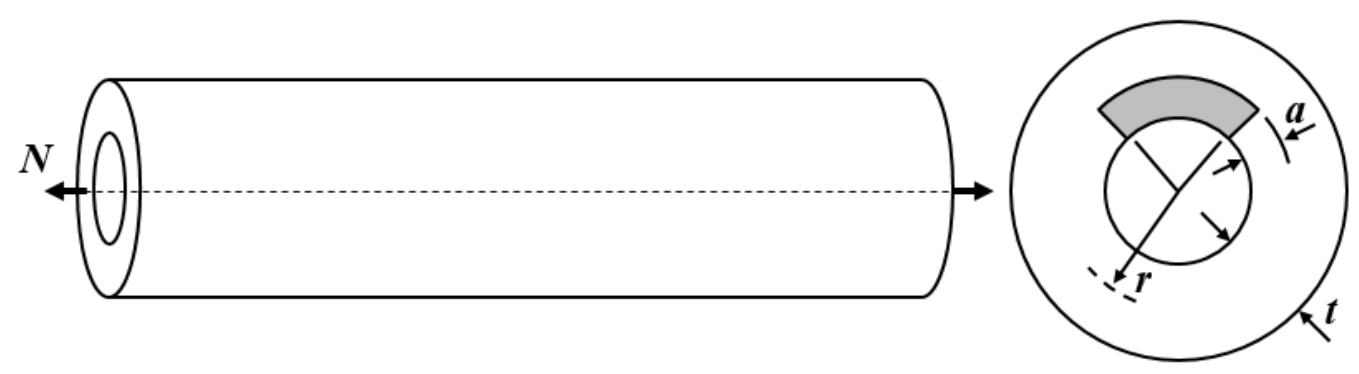

Fig. 1. Schematic of a circumferentially cracked pipe subject to axial tension.

\subsection{Mechanical and Thermal Loading Conditions}

The cracked pipe is subject to combined mechanical (primary) and thermal (secondary) loadings. For the mechanical loading, axial tension $\mathrm{N}$ is considered (Fig. 1). For thermal loading, two different types of temperature gradient are considered, as depicted in Fig. 2. The first type is a "radial temperature gradient" (Fig. 2a), and the second type a "sectional temperature gradient" (Fig. 2b). The magnitude of the maximum temperature difference, $\Delta \mathrm{T}_{\max }$, is varied to produce different thermal loading magnitudes. As the loading history can affect the elastic-plastic value of $\mathrm{J}$, two loading sequences are considered; (i) thermal loading applied first, followed by mechanical loading (this case will be referred to as $\mathrm{T} \rightarrow \mathrm{M}$ ) and (ii) mechanical loading applied first followed by thermal loading (referred to as $\mathrm{M} \rightarrow \mathrm{T}$ ) 


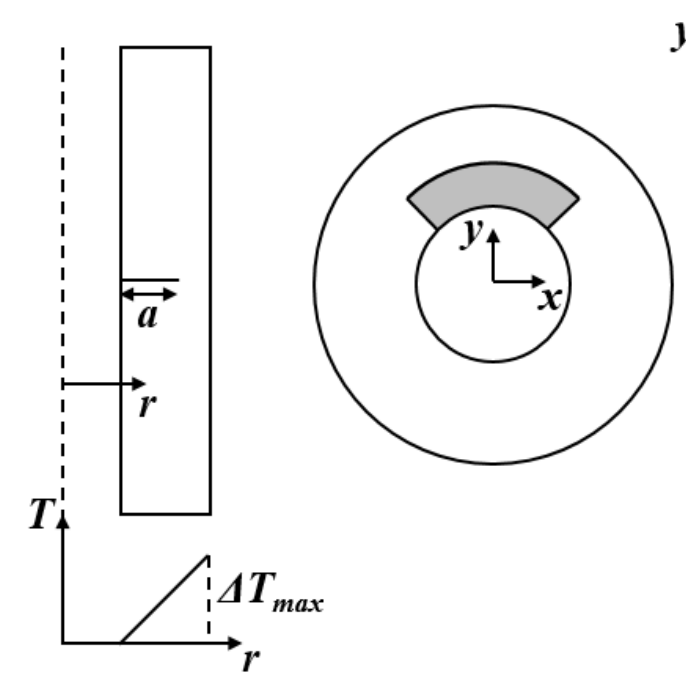

(a)

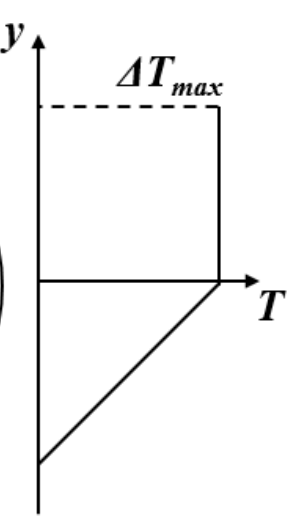

(b)

Fig. 2. Types of thermal loading considered in this work: (a) radial temperature gradient and (b) sectional temperature gradient.

\subsection{FE analysis}

Elastic and elastic-plastic FE analyses were performed using ABAQUS [7]. Considering symmetry conditions, a quarter model was used. Twenty-node isoparametric quadratic brick elements with reduced integrations (C3D20R in ABAQUS) were used. A typical FE mesh is shown in Fig. 3. The crack tip was designed with collapsed elements and a ring of wedge-shaped elements was used in the crack-tip region. The number of elements and nodes were about 10,000 and 47,000, respectively. A total of forty-six elements was used through the thickness. As shown in Fig. 3, round corners with a finite radius, rather than sharp corner, were modelled, but this does not affect the fracture mechanics calculations for $J$ at the centre of the crack.

Elastic FE analyses were performed first to determine the relative magnitude of thermal stress, $\beta$ (see Eq. (5)). It should be noted that both $\mathrm{K}_{\mathrm{I}}^{\mathrm{p}}$ and $\mathrm{L}_{\mathrm{r}}$ are directly proportional to the magnitude of the primary load and therefore $\beta$ is independent of the magnitude of primary loading. The value of $\mathrm{L}_{r}$ is determined using the R6 limit load solutions [1]. For elastic analyses, an isotropic material was assumed with Young's modulus E=200GPa and Poisson's ratio $v=0.3$.

Based on elastic analysis, the following four different values of $\beta$ were considered: $\beta=0.5,2.0,4.0$ and 6.0 . The value $\beta=0.5$ represents small thermal loading and the value $\beta=6.0$ represents large thermal loading; a mechanical load corresponding to six times the plastic yield load $\left(\mathrm{L}_{\mathrm{r}}=6.0\right)$ would be required to generate the same stress intensity factor. 
For each value of $\beta$, elastic-plastic FE analyses were performed for combined mechanical and thermal loading. The following Ramberg-Osgood relationship with the isotropic hardening rule was used to describe the material behaviour:

$$
\varepsilon=\frac{\sigma}{\mathrm{E}}+\alpha\left(\frac{\sigma_{\mathrm{y}}}{\mathrm{E}}\right)\left(\frac{\sigma}{\sigma_{\mathrm{y}}}\right)^{\mathrm{n}}
$$

where $\alpha$ and $\mathrm{n}$ are Ramberg-Osgood parameters and $\sigma_{\mathrm{y}}$ denotes the yield ( $0.2 \%$ proof) strength. The value of $\sigma_{\mathrm{y}}$ was taken as $300 \mathrm{MPa}$ and to be consistent with the definition of $\sigma_{\mathrm{y}}$ as the $0.2 \%$ proof stress, $\alpha$ was then chosen as

$$
\alpha=\frac{0.002 \mathrm{E}}{\sigma_{\mathrm{y}}}\left(=\frac{4}{3}\right)
$$

To investigate the effect of the strain hardening exponent, three different values of $n$ were considered: $\mathrm{n}=5,10$ and 20 .

Values of the J-integral were extracted from the FE results at the deepest position of the crack using a domain integral as a function of the applied load (see Fig. 1). Numerical $J$ estimates using ABAQUS are generally known to be robust even for thermal stress problems and $J$ values show path independence for all cases reported in this paper.

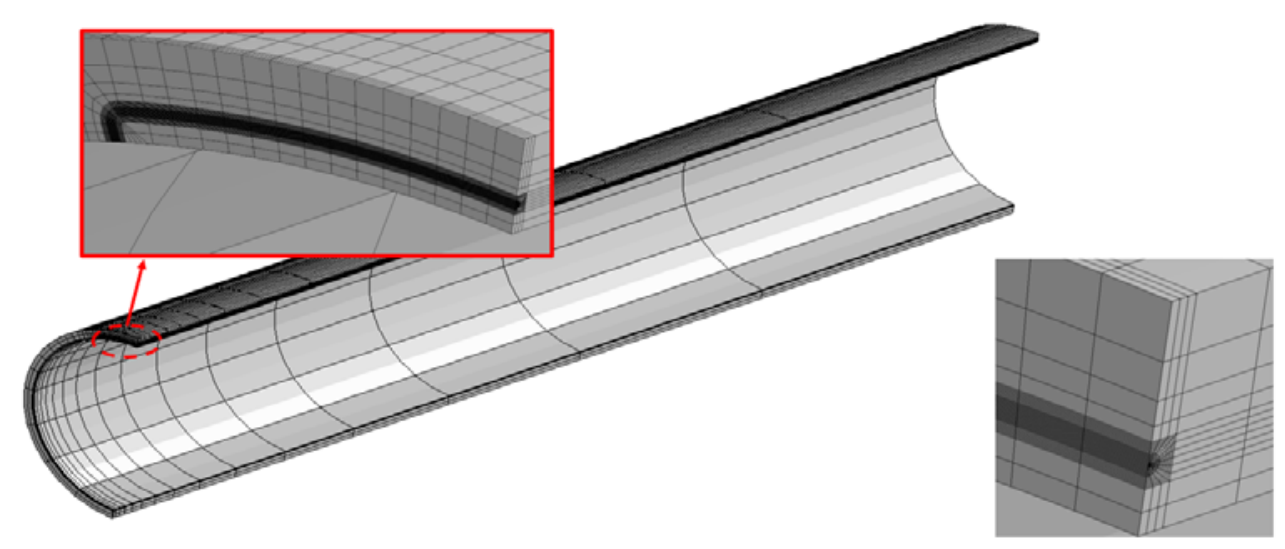

Fig. 3. A typical FE mesh for a part-through surface crack.

\section{FINITE ELEMENT RESULTS}

\subsection{FE Results for $V_{0}$ for Secondary Loading Acting Alone}

The values of $V_{o}$ were calculated from the values of $J$ obtained from elastic and elastic-plastic analysis under thermal loading only (see Eq. (6) for the definition). Results are given in Table 1 for the radial temperature gradient and in Table 2 for the sectional temperature gradient. Note, that for some cases of deep cracks, $\mathrm{a} / \mathrm{t}=0.7$, the 
FE analyses did not converge due to the large bending stress and only limited solutions are given in Table 2.

Table 1. Results for $\mathrm{V}_{\mathrm{o}}$ for the radial temperature gradient.

\begin{tabular}{|c|c|c|c|c|c|c|c|c|}
\hline \multirow{2}{*}{$r / t$} & \multirow{2}{*}{$\theta / \pi$} & \multirow{2}{*}{$a / t$} & \multirow{2}{*}{$\mathrm{n}$} & \multicolumn{4}{|c|}{$\beta$} & \multirow{2}{*}{$\begin{array}{l}V_{o, \max } \\
(\text { at } \beta)\end{array}$} \\
\hline & & & & 0.5 & 2 & 4 & 6 & \\
\hline 5 & 0.125 & 0.3 & 20 & 0.82 & 0.82 & 0.65 & 0.55 & $1.00(0.7)$ \\
\hline \multirow{6}{*}{10} & 0.0625 & 0.3 & 20 & 1.00 & 0.82 & 0.65 & 0.55 & $1.01(0.7)$ \\
\hline & \multirow{4}{*}{0.125} & \multirow{3}{*}{0.3} & 5 & 0.99 & 0.80 & 0.67 & 0.59 & $1.00(0.3)$ \\
\hline & & & 10 & 1.01 & 0.85 & 0.68 & 0.59 & $1.01(0.6)$ \\
\hline & & & 20 & 1.01 & 0.88 & 0.70 & 0.60 & $1.02(0.7)$ \\
\hline & & 0.5 & 20 & 1.01 & 0.75 & 0.55 & 0.45 & $1.01(0.6)$ \\
\hline & 0.25 & 0.3 & 20 & 1.01 & 0.93 & 0.75 & 0.64 & $1.03(0.9)$ \\
\hline 20 & 0.125 & 0.3 & 20 & 1.01 & 0.94 & 0.76 & 0.64 & $1.05(0.8)$ \\
\hline
\end{tabular}

Table 2. Results for $\mathrm{V}_{\mathrm{o}}$ for the sectional temperature gradient.

\begin{tabular}{|c|c|c|c|c|c|c|c|c|}
\hline \multirow{2}{*}{$r / t$} & \multirow{2}{*}{$\theta / \pi$} & \multirow{2}{*}{$a / t$} & \multirow{2}{*}{$\mathrm{n}$} & \multicolumn{4}{|c|}{$\beta$} & \multirow{2}{*}{$\begin{array}{l}V_{o, \max } \\
(\text { at } \beta)\end{array}$} \\
\hline & & & & 0.5 & 2 & 4 & 6 & \\
\hline 5 & 0.125 & 0.3 & 20 & 1.01 & 0.90 & 0.66 & 0.55 & $1.10(0.9)$ \\
\hline \multirow{7}{*}{10} & 0.0625 & 0.3 & 20 & 1.03 & 0.99 & 0.76 & 0.63 & $1.13(1.1)$ \\
\hline & \multirow{5}{*}{0.125} & \multirow{3}{*}{0.3} & 5 & 1.02 & 0.80 & 0.64 & 0.55 & $1.02(0.5)$ \\
\hline & & & 10 & 1.04 & 0.94 & 0.73 & 0.62 & $1.11(0.9)$ \\
\hline & & & 20 & 1.04 & 1.11 & 0.85 & 0.71 & $1.25(1.1)$ \\
\hline & & 0.5 & 20 & 1.06 & 1.13 & 0.89 & 0.75 & $1.24(1.2)$ \\
\hline & & 0.7 & 20 & 1.09 & 1.29 & 1.04 & 0.88 & $1.37(1.3)$ \\
\hline & 0.25 & 0.3 & 20 & 1.04 & 1.23 & 0.97 & 0.82 & $1.32(1.3)$ \\
\hline 20 & 0.125 & 0.3 & 20 & 1.05 & 1.44 & 1.10 & 0.91 & $1.54(1.4)$ \\
\hline
\end{tabular}

It can be seen from these tables that $\mathrm{V}_{\mathrm{o}} \leq 1.0$ in most cases, i.e. that plasticity leads to a reduction in $\mathrm{J}$, or a reduction in effective stress intensity factor, relative to elastic loading. However, in some cases, particularly for the sectional temperature gradient, $\mathrm{V}_{\mathrm{o}}>1.0$, showing a plastic enhancement of effective stress intensity factor.

The value of $\mathrm{V}_{\mathrm{o}}$ is unity for small loadings, where response is elastic, and is less than unity at very large loadings, where plasticity leads to relaxation of the high elastic stresses. In addition to the tabulated results, solutions were obtained for intermediate magnitudes of thermal loading. Figure 4 shows selected $\beta-V_{0}$ curves from $\mathrm{FE}$ analyses. As shown in Fig. 4, $\mathrm{V}_{\mathrm{o}, \max }$ is the maximum value in the curve. Tables 1 and 2 include the $\mathrm{V}_{\mathrm{o} \text {,max }}$ values obtained from $\mathrm{FE}$ analysis, together with the $\beta$ value where the $V_{o, \max }$ occurs. 


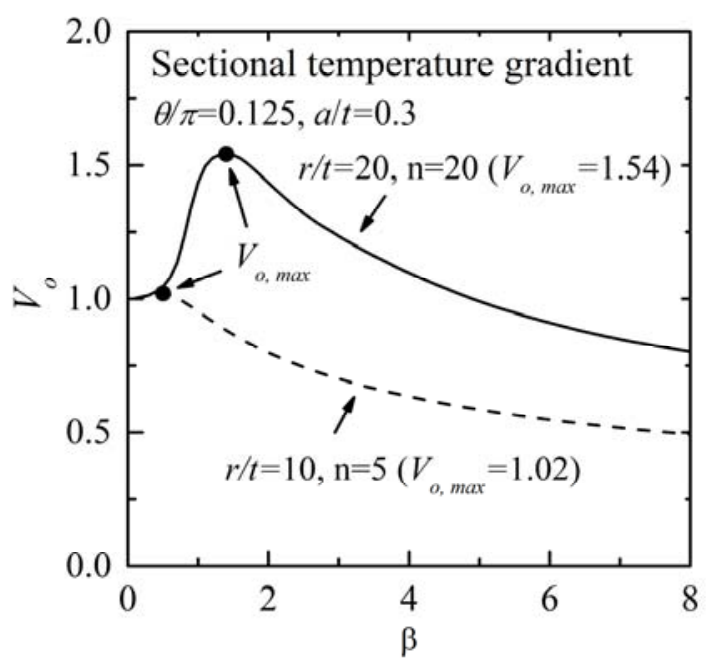

Fig. 4. Selected $V_{o}$ profile results for sectional temperature gradient.

\subsection{FE Results for Combined Loading}

The values of $\mathrm{J}$ were also calculated from elastic and elastic-plastic FE analyses under combined mechanical and thermal loadings leading to corresponding values of the parameter $\mathrm{J}$ evaluated using

$$
\mathrm{V}=\sqrt{\frac{\mathrm{J}_{\mathrm{e}}^{\mathrm{p}}}{\mathrm{J}^{\mathrm{s}}}}\left(\sqrt{\frac{\mathrm{J}^{\mathrm{p}+\mathrm{s}}}{\mathrm{J}^{\mathrm{p}}}-1}\right)
$$

where $\mathrm{J}^{\mathrm{p}}$ and $\mathrm{J}^{\mathrm{p}+\mathrm{s}}$ denote the values of $\mathrm{J}$ due to mechanical loading and combined loading, respectively. Selected results of $\mathrm{V} / \mathrm{V}_{\mathrm{o}}$ are plotted in Fig. 5. For small thermal loading, Fig. 5a, there is little effect of loading sequence but the value of $\mathrm{V}$ increases significantly from its initial value $\left(\mathrm{V}_{\mathrm{o}}=1\right.$ in this case) with increasing plasticity (increasing $\mathrm{L}_{\mathrm{r}}$ ). For larger thermal loadings, Fig. 5b, the loading sequence is more important with mechanical loading applied first $(\mathrm{M} \rightarrow \mathrm{T})$ leading to higher values of $\mathrm{J}^{\mathrm{p}+\mathrm{s}}$ than for secondary loading applied first $(\mathrm{T} \rightarrow \mathrm{M})$. Further FE results are presented in Section 5, where they are compared with the estimates in Part 1. 


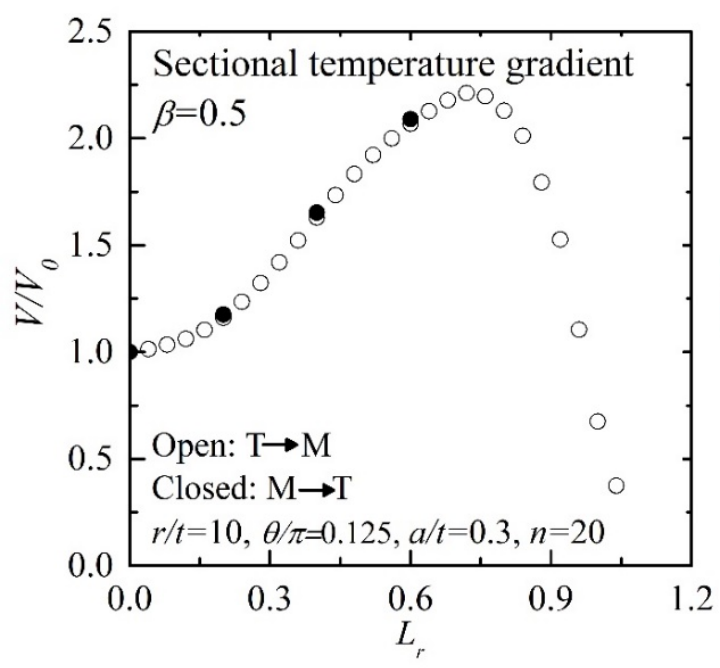

(a)

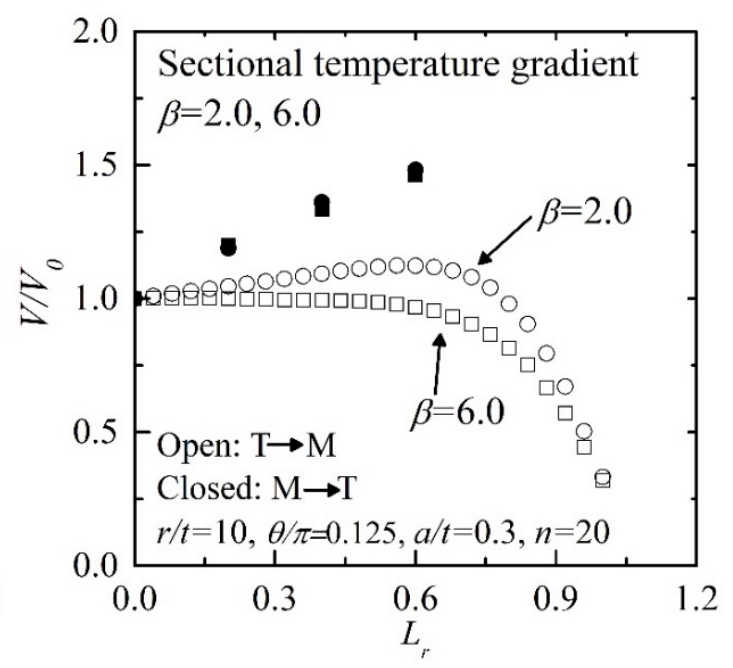

(b)

Fig. 5. Selected results for FE $V / \mathrm{V}_{\mathrm{o}}$ : (a) small thermal loading $(\beta=0.5)$ and (b) large thermal loading $(\beta=2$ and 6$)$.

\section{COMPARISON OF FE RESULTS AND SIMPLIFIED ESTIMATES}

\subsection{Elastic Follow-up Comparisons}

In Part 1, it is noted that the elastic follow-up factor evaluated for secondary stresses only, $Z^{\text {s }}$, is related to the variation of $V_{o}$ with secondary load magnitude, $\beta$ in Eq. (5), for a given stress-strain curve, i.e. for a given material. Specifically, a secondary reference stress, $\sigma_{\text {ref }}^{\mathrm{s}}$, is evaluated from

$$
\beta \mathrm{V}_{\mathrm{o}}=\left(\sigma_{\text {ref }}^{\mathrm{s}} / \sigma_{\mathrm{y}}\right) / \mathrm{f}\left(\sigma_{\text {ref }}^{\mathrm{s}} / \sigma_{\mathrm{y}}\right)
$$

where $\mathrm{f}\left(\sigma_{\text {ref }}^{\mathrm{s}} / \sigma_{\mathrm{y}}\right)$ is the Option 2 failure assessment curve, which depends on the material stress-strain curve through

$$
\mathrm{f}\left(\sigma_{\text {ref }}^{\mathrm{s}} / \sigma_{\mathrm{y}}\right)=\left[\frac{\mathrm{E} \varepsilon_{\text {ref }}^{\mathrm{s}}}{\sigma_{\text {ref }}^{\mathrm{s}}}+\frac{(1 / 2)\left(\sigma_{\text {ref }}^{\mathrm{s}} / \sigma_{\mathrm{y}}\right)^{2}}{E \varepsilon_{\text {ref }}^{\mathrm{sef}} / \sigma_{\text {ref }}^{\mathrm{s}}}\right]^{-1 / 2}=\left(\mathrm{J}^{\mathrm{s}} / \mathrm{J}_{\mathrm{e}}^{\mathrm{s}}\right)^{1 / 2}
$$

where, $\varepsilon_{\text {ref }}^{\mathrm{s}}$ is the strain at the secondary reference stress from the stress-strain curve, i.e. from Eq. (8) for the present calculations. Note, that when the small-scale yielding correction is neglected in Eq. (12), the approach reduces to that proposed by Roche [8]

$$
\mathrm{J}^{\mathrm{s}}=\mathrm{J}_{\mathrm{e}}^{\mathrm{s}}\left[\frac{\sigma_{\text {ref }}^{\mathrm{s}} \varepsilon_{\text {ref }}^{\mathrm{s}}}{\sigma_{\text {ref }}^{\mathrm{s}, \mathrm{el}} \varepsilon_{\text {ref }}^{\mathrm{s}, \mathrm{el}}}\right]=\mathrm{J}_{\mathrm{e}}^{\mathrm{s}} \mathrm{V}_{\mathrm{o}}^{2}
$$


where, $\sigma_{\text {ref }}^{\mathrm{s}, \mathrm{el}}$ and $\varepsilon_{\text {ref }}^{\mathrm{s}, \mathrm{el}}$ denote elastic estimates of reference stress and strain for secondary loading, respectively. As the material follows the Ramberg-Osgood relationship of Eq. (8), $\sigma_{\text {ref }}^{\mathrm{s}}$ and $\varepsilon_{\text {ref }}^{\mathrm{s}}$ can be easily calculated, and $\mathrm{Z}$ is then determined using [5]

$$
Z=1+\frac{E \varepsilon_{\text {ref }}^{\mathrm{s}}-\sigma_{\text {ref }}^{\mathrm{sel}}}{\sigma_{\mathrm{ref}}^{\mathrm{sel}}-\sigma_{\mathrm{ref}}^{\mathrm{s}}}
$$

Note that the superscript ' $\mathrm{s}$ ' in $\mathrm{Z}$ is dropped here and elsewhere in this paper as elastic follow-up is only calculated for secondary loading acting alone and it is assumed that the same value can be used to estimate J under combined loading. Resulting values of $\mathrm{Z}$ are given in Tables 3 and 4 for the radial temperature gradient and sectional temperature gradient, respectively. It can be seen that the cases considered cover a wide range of elastic follow-up with $Z$ values from 1.1 to 7 , the higher values being for the sectional temperature gradient. Generally the value of $Z$ tends to increase with increasing $r / t, \theta / \pi, a / t$ and $n$. It is noted that the method of estimating $Z$ in [9], based on the approach of [8] leads to very similar results to those in Tables 3 and 4, particularly for higher thermal loads.

In Part 1 , it was suggested that the dependence of $\mathrm{V}_{0}$ on $\beta$ is relatively weakly affected by material properties and therefore that the elastic follow-up factor $Z$ can be estimated by neglecting small-scale-yielding corrections from Eq. (11) and

$$
\beta=\sigma_{\text {ref }}^{\mathrm{s}} / \sigma_{\mathrm{y}}+\frac{1}{\mathrm{Z}}\left(\frac{\sigma_{\text {ref }}^{\mathrm{s}} / \sigma_{\mathrm{y}}}{\mathrm{f}^{2}\left(\sigma_{\text {ref }}^{\mathrm{s}} / \sigma_{\mathrm{y}}\right)}-\sigma_{\text {ref }}^{\mathrm{s}} / \sigma_{\mathrm{y}}\right)
$$

using the R6 Option 1 failure assessment curve

$$
f(x)=\left(1+0.5 x^{2}\right)^{-1 / 2}\left[0.3+0.7 \exp \left(-0.6 x^{6}\right)\right]
$$

which is independent of material properties. Figure 6 compares these estimates of Z, denoted 'Option 1' with the values from the FE results deduced as described earlier, denoted 'Option 2', for selected cases. It can be seen that the simplified estimate using the Option 1 curve is in close agreement with the FE results.

Table 3. FE results for $\mathrm{Z}$ for the radial temperature gradient, based on the procedure in $[5]$.

\begin{tabular}{|c|c|c|c|c|c|c|}
\hline $\mathrm{r} / \mathrm{t}$ & \multirow{2}{*}{$\theta / \pi$} & $\mathrm{a} / \mathrm{t}$ & \multirow{2}{*}{$\mathrm{n}$} & \multicolumn{3}{|c|}{$\beta$} \\
\cline { 5 - 7 } & & & & 2 & 4 & 6 \\
\hline 5 & 0.125 & 0.3 & 20 & 1.5 & 1.8 & 1.8 \\
\hline 10 & 0.0625 & 0.3 & 20 & 1.5 & 1.8 & 1.8 \\
\hline
\end{tabular}




\begin{tabular}{|l|c|c|c|c|c|c|}
\hline \multirow{3}{*}{} & \multirow{3}{*}{0.125} & \multirow{2}{*}{0.3} & 5 & 1.4 & 1.5 & 1.6 \\
\cline { 3 - 7 } & & 10 & 1.6 & 1.8 & 1.9 \\
\cline { 3 - 7 } & & 20 & 2.3 & 2.1 & 2.1 \\
\cline { 3 - 7 } & 0.5 & 20 & 1.1 & 1.2 & 1.1 \\
\hline & 0.25 & 0.3 & 20 & 2.2 & 2.4 & 2.5 \\
\hline 20 & 0.125 & 0.3 & 20 & 2.3 & 2.5 & 2.5 \\
\hline
\end{tabular}

Table 4. FE results for $\mathrm{Z}$ for the sectional temperature gradient, based on the procedure in [5].

\begin{tabular}{|c|c|c|c|c|c|c|}
\hline \multirow{2}{*}{$\mathrm{r} / \mathrm{t}$} & \multirow{2}{*}{$\theta / \pi$} & \multirow{2}{*}{$a / t$} & \multirow{2}{*}{$\mathrm{n}$} & \multicolumn{3}{|c|}{$\beta$} \\
\hline & & & & 2 & 4 & 6 \\
\hline 5 & 0.125 & 0.3 & 20 & 2.0 & 1.8 & 1.8 \\
\hline \multirow{7}{*}{10} & 0.0625 & 0.3 & 20 & 2.7 & 2.5 & 2.4 \\
\hline & \multirow{5}{*}{0.125} & \multirow{3}{*}{0.3} & 5 & 1.3 & 1.4 & 1.4 \\
\hline & & & 10 & 2.5 & 2.1 & 2.1 \\
\hline & & & 20 & 3.6 & 3.2 & 3.0 \\
\hline & & 0.5 & 20 & 3.9 & 3.6 & 3.5 \\
\hline & & 0.7 & 20 & 5.4 & 4.9 & 4.8 \\
\hline & 0.25 & 0.3 & 20 & 4.8 & 4.3 & 4.1 \\
\hline 20 & 0.125 & 0.3 & 20 & 7.0 & 5.5 & 5.1 \\
\hline
\end{tabular}

It should be noted that both the FE $\mathrm{Z}$ estimation procedure given in Ref. [9] and the estimation equations given above can be applied only when $\beta>1$. The case of $\beta<1$ is discussed separately in Section 6 below.

It can be seen from Tables 3 and 4 that the elastic follow-up factor is not strongly dependent on the magnitude of the loading. On this basis, it was proposed in [5] that a possible approach would be to evaluate $V_{0}$ for a large secondary stress (of elastic magnitude $\beta=6$ so that elastic effects are small) and then to estimate $Z$ from

$$
\mathrm{Z}=10 \mathrm{~V}_{\mathrm{o}}-4.4 ; \quad \beta=6
$$

provided the result is in the range 3 to 10, i.e. elastic follow-up is large. Application of Eq. (17) is also shown in Fig. 6. This fits well for the case of $\beta=6$ but overestimates elastic follow-up for other cases. It therefore provides a conservative method for estimating the elastic follow-up factor from an elastic-plastic analysis of secondary loading. 


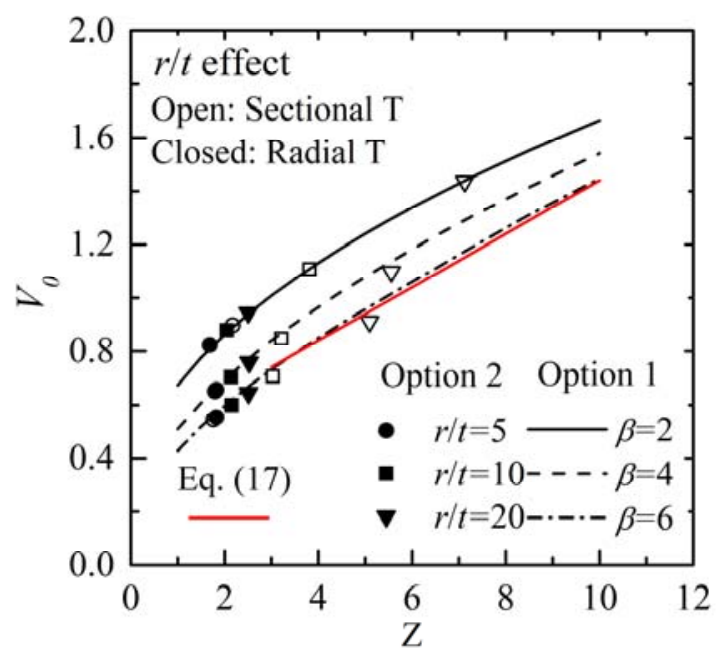

(a)

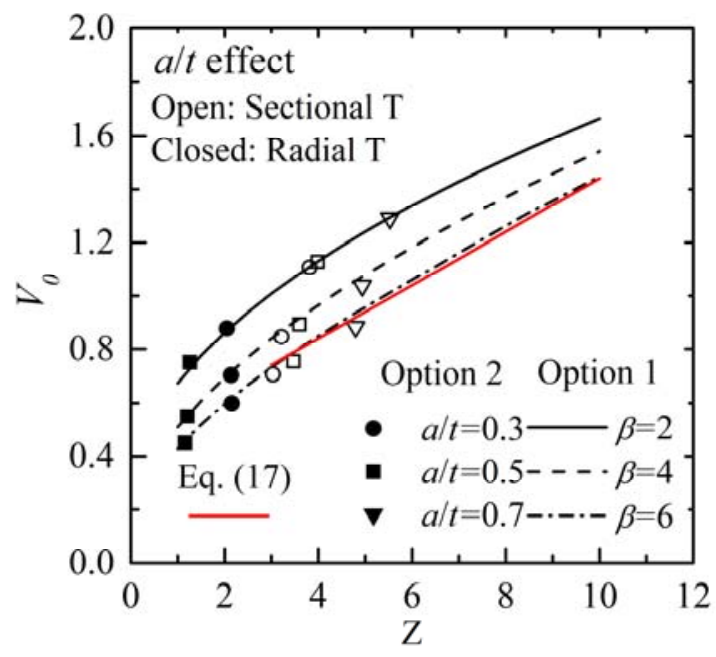

(c)

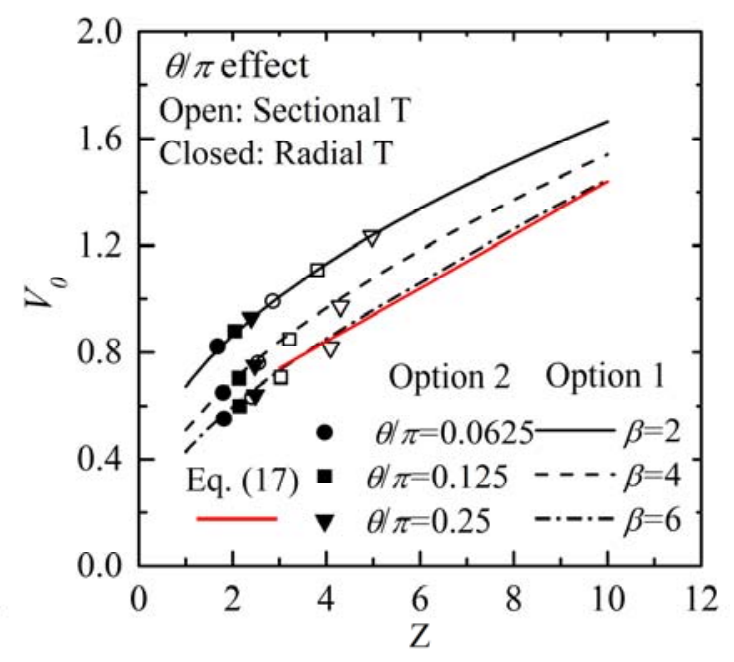

(b)

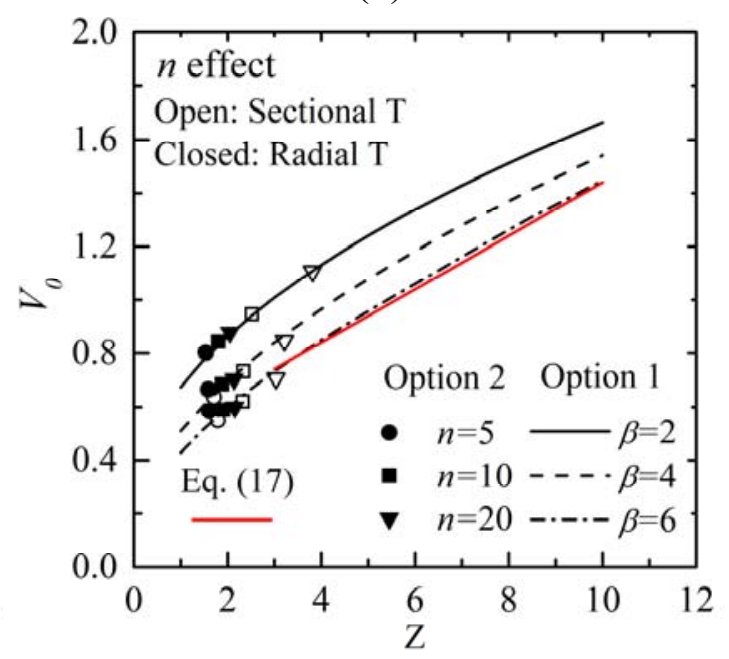

(d)

Fig. 6. Comparison of $\mathrm{Z}$ estimates using Option 1 and Option 2 approaches and the simplified method of Eq. (17): effect of (a) r/t, (b) $\theta / \pi$, (c) a/t and (d) $n$.

\subsection{J Comparisons for large secondary loading $(\beta>1)$}

In this section, the $\mathrm{J}$ estimates obtained using the estimates in Part 1 [5] are compared with the FE results. The comparisons for $\mathrm{J}$ are made using the corresponding values of $\mathrm{V}$. Only large secondary loads $(\beta>1)$ are considered with smaller loads being addressed in Section 6.

\subsubsection{Results for thermal loading applied first}

Comparison of the $\mathrm{V}$ estimation equations with $\mathrm{FE}$ analyses for the $\mathrm{T} \rightarrow \mathrm{M}$ loading sequence under large thermal loading is presented in this sub-section. The results depend on $\mathrm{Z}$ with those for moderate $\mathrm{Z}(\leq 3)$ given in Figs. 7 and 8, and those 
for large $Z(>3)$ in Fig. 9. Note that the $\mathrm{V}$ estimates were calculated using the Option 1 failure assessment curve of Eq. (14).

It can be seen from Figs. 7 and 8, that the V-factor estimation equation for moderate Z, $\mathrm{V}^{(2)}$ (see Eq. (2)), conservatively estimates the FE results. The estimated $\mathrm{V}$ factors tend to be more conservative for lower $\mathrm{Z}$ and for larger $\mathrm{L}_{\mathrm{r}}$. It should be noted that the $\mathrm{V}^{(2)}$ expression was derived as a upper bound estimate for moderate $\mathrm{Z}$ [3], $Z \leq 3$, and that when $Z$ approaches $Z=3$, the estimate is accurate, Fig. $8 b$.

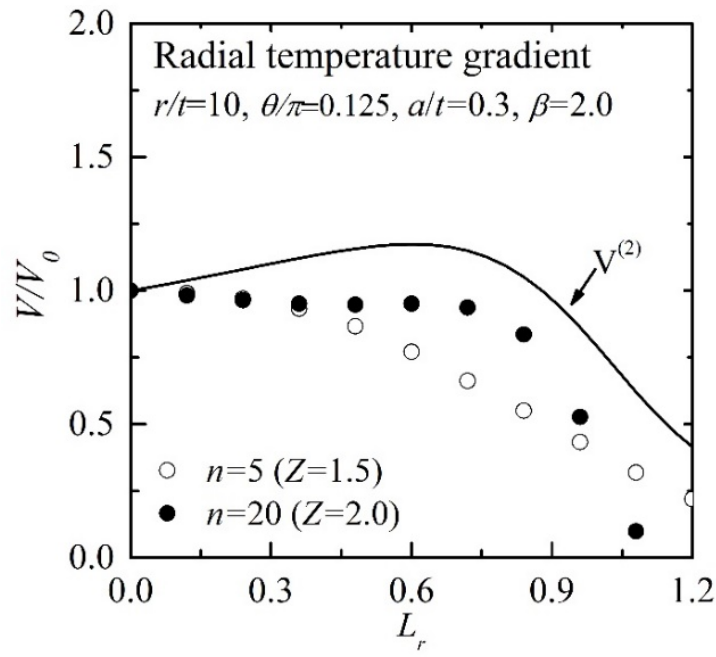

(a)

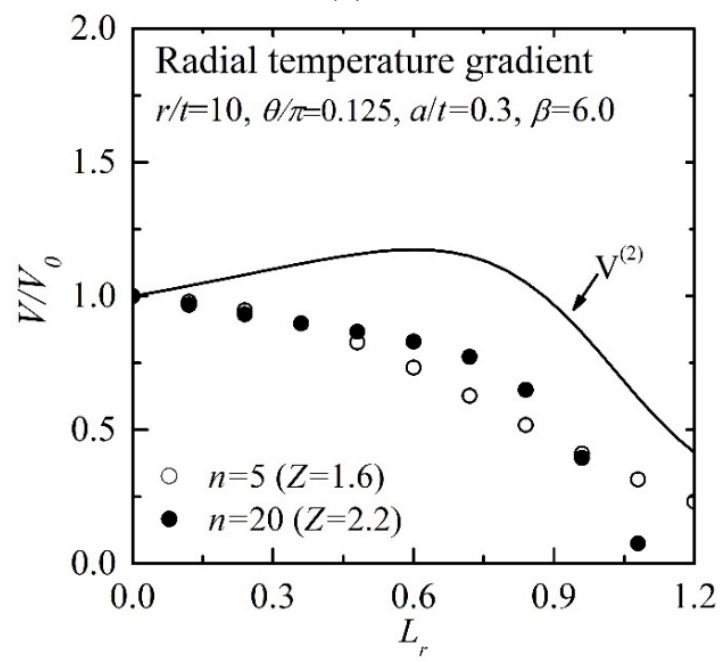

(c)

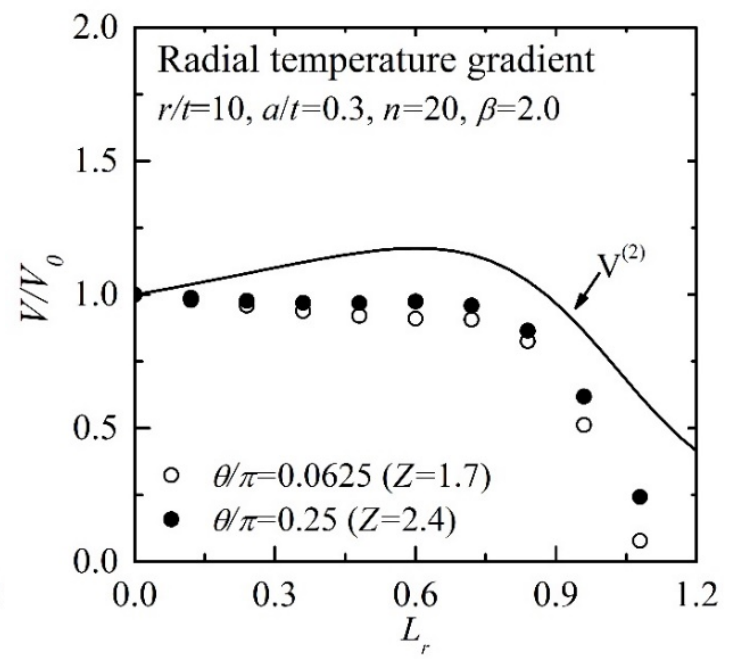

(b)

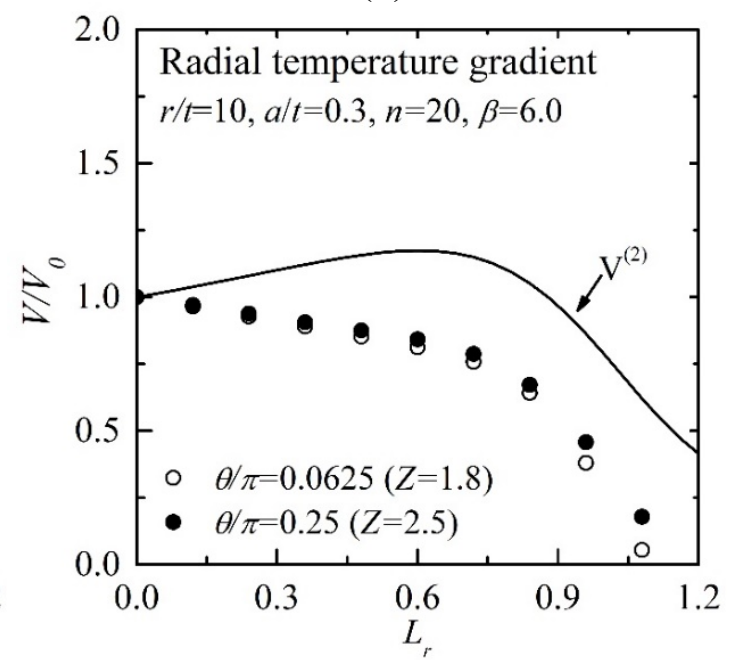

(d)

Fig. 7. Comparison of $F E V / V_{o}$ results with estimated ones for moderate $Z$ for $T \rightarrow M$ loading sequence for radial temperature gradient: (a)-(b) $\beta=2$ and (c)-(d) $\beta=6$.

The results in Fig. 9 show that the V-factor estimation equation for large Z, $\mathrm{V}^{(4)}$ (see Eq. (7)), gives accurate estimates for small $\mathrm{L}_{\mathrm{r}} \quad\left(\mathrm{L}_{\mathrm{r}} \leq 0.7\right)$ but gives more conservative estimates for larger $\mathrm{Lr}$, suggesting that plasticity leads to greater relaxation of secondary stresses than implicit in Eq. (7). As shown in Fig. 9, the $\mathrm{V} / \mathrm{V}_{\mathrm{o}^{-}}$ 
$\mathrm{L}_{r}$ curves are similar for the different geometries and crack sizes, possibly because those effects were already included in the estimation equations for $V_{o}$ and $Z$. It seems that the magnitude of thermal loading would be a more important factor.

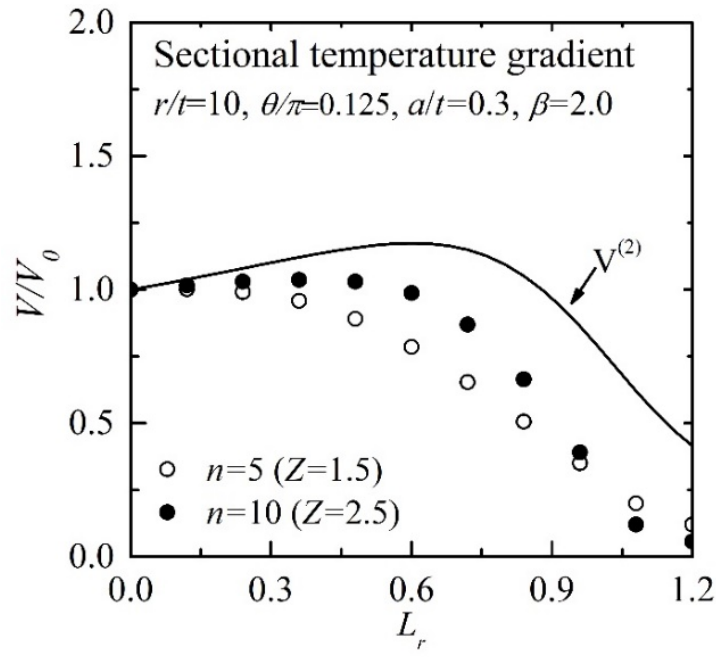

(a)

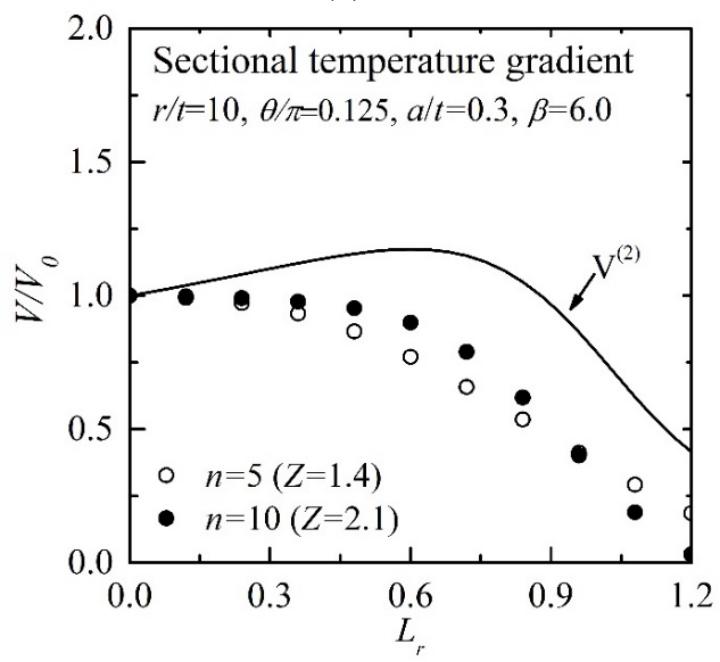

(c)

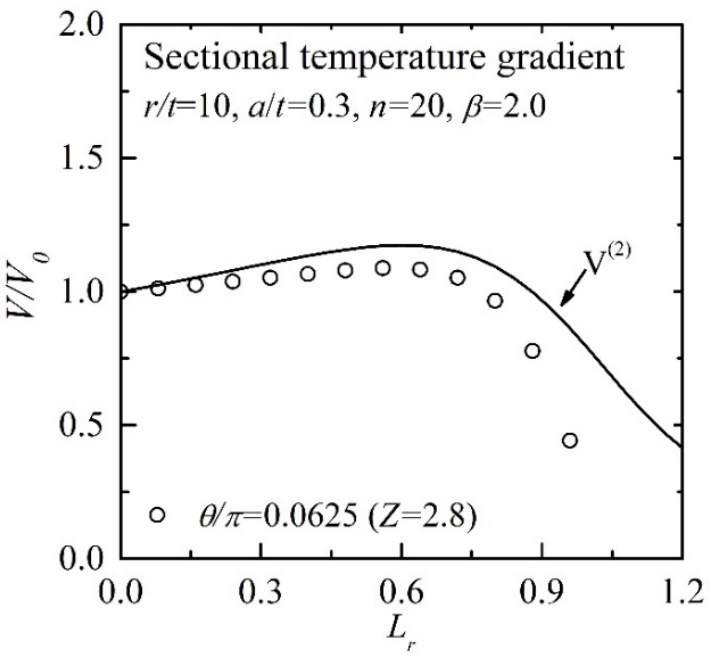

(b)

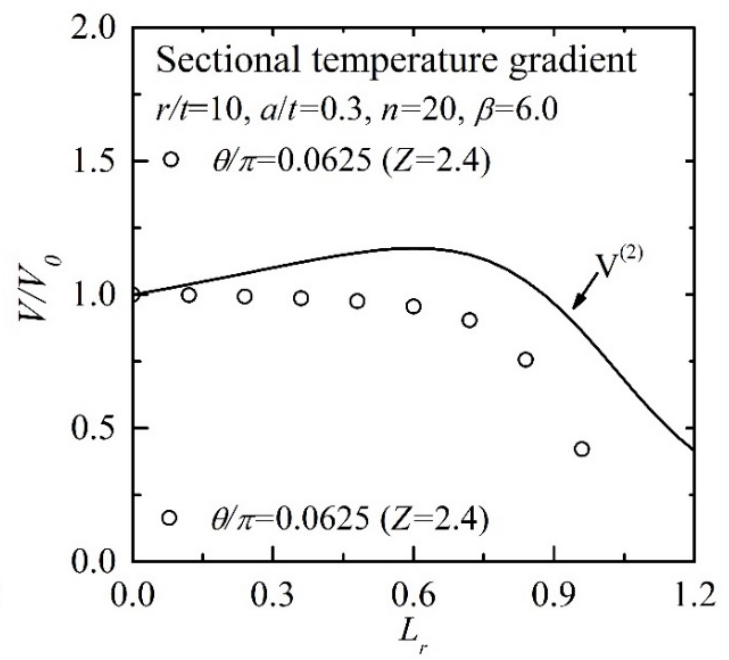

(d)

Fig. 8. Comparison of FE V/Vosults with estimated ones for moderate $Z$ for $T \rightarrow M$ loading sequence for sectional temperature gradient: (a)-(b) $\beta=2$ and (c)-(d) $\beta=6$. 


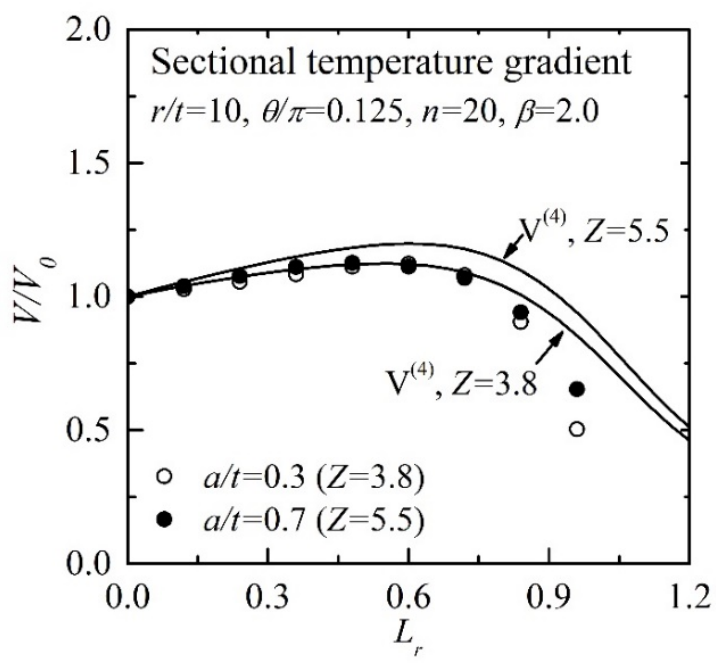

(a)

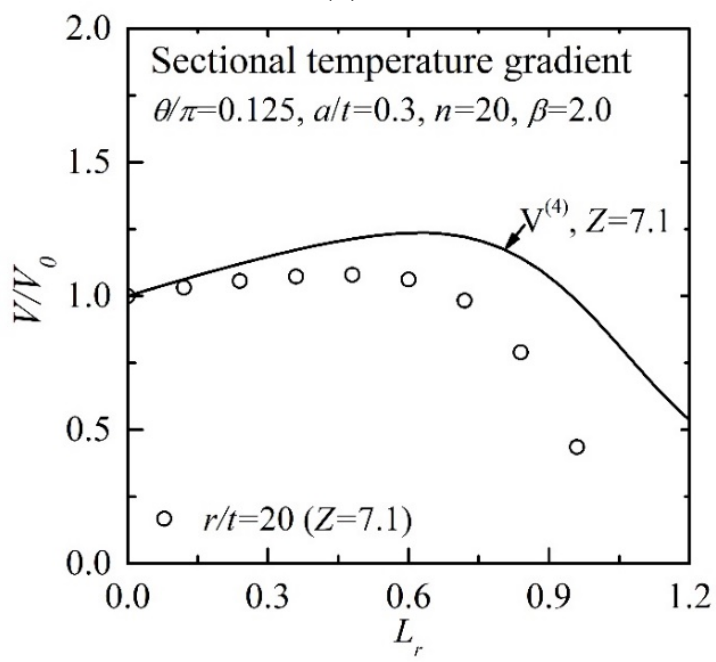

(c)

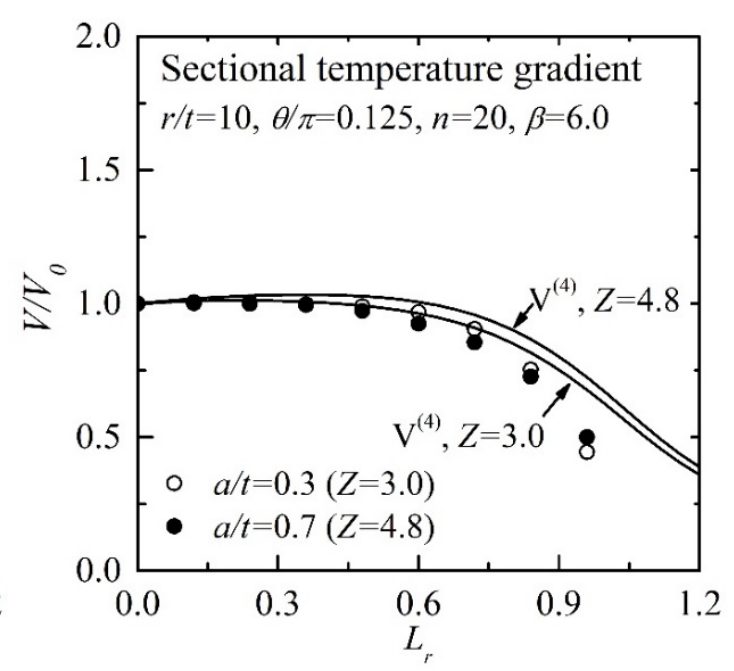

(b)

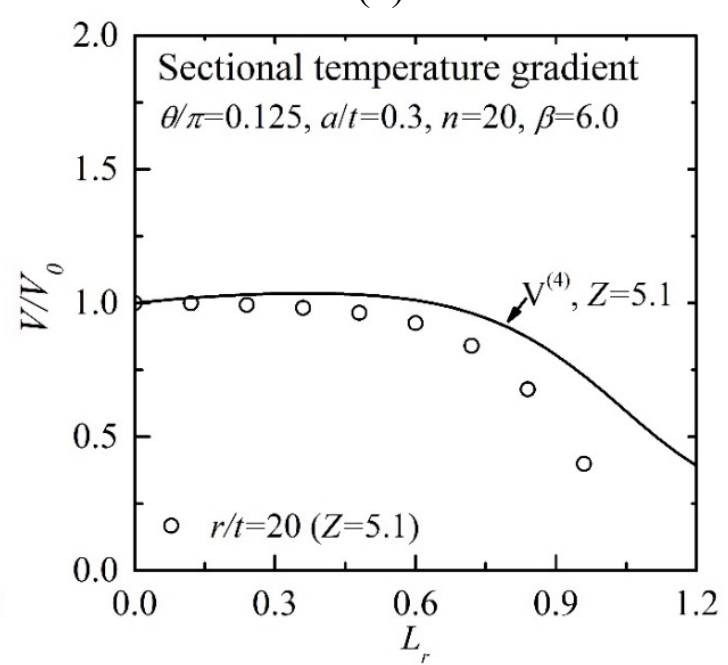

(d)

Fig. 9. Comparison of $F E V / V_{o}$ results with estimated ones for large $Z(>3)$ for $T \rightarrow M$ loading sequence; (a)-(b) a/t effect, and (c)-(d) r/t effect.

\subsubsection{Results for mechanical loading applied first}

Comparison of the $\mathrm{V}$-factor estimation equations with $\mathrm{FE}$ analyses for the $\mathrm{M} \rightarrow \mathrm{T}$ loading sequence under large thermal loading is presented in this sub-section; Fig. 10 and 11 for moderate $Z(Z \leq 3)$ and Fig. 12 for large $Z(Z>3)$. Figure 10 presents results for cases where the maximum value of $V_{o}, V_{o, m a x}$, over a range of thermal loads is unity. Figures 11 and 12 correspond to cases where $V_{o, \max }>1$.

The results in Fig. 10 show that the equation for moderate $\mathrm{Z}, \mathrm{V}^{(2)}$, reproduces the trend in the FE results but can lead to some underestimate of $\mathrm{V}$, and hence $\mathrm{J}$, when the stress-strain curve is very flat, $\mathrm{n}=20$. However, the differences are generally small. 
The results in Figs. 11 and 12 show that the estimated $\mathrm{V}$ using $\mathrm{V}^{(2)}$ or $\mathrm{V}^{(4)}$ can be non-conservative. The non-conservatism in these cases is again for $n=20$ but occurs even for small primary loads. Furthermore, Figure 12 shows that the estimate $\mathrm{V}^{(4)}$ does not reproduce the trend in the FE data, showing too weak a dependence on the primary load level, $\mathrm{Lr}$.

In our previous works $[4,8]$, it has been suggested that the maximum value of $\mathrm{V}_{\mathrm{o}}, \mathrm{V}_{\mathrm{o}, \max }$, is a good indicator of elastic-plastic response under combined loading. The results in Figs. 11 and 12 for $V_{o, \max }>1.0$ do not show a clear dependence on $V_{o, \max }$ but do show a difference in behaviour from those in Fig. 10 for $\mathrm{V}_{\mathrm{o}, \max }=1$. The results also show little dependence on the thermal load magnitude or level of elastic followup. Therefore, it is suggested here that Eq.(7) can be simplified by removing the dependence on $\beta$ and $Z$ by taking specific values $\beta=1.0$ and $Z=3.0$. With the further simplification of setting $f(\beta)=1.0$, this leads to a new estimate for $V_{o, \max }>1$

$$
\mathrm{V}^{(5)} / \mathrm{V}_{0}=\mathrm{f}\left(\mathrm{L}_{\mathrm{r}}\right)+\frac{1}{3}\left[\frac{\left(\mathrm{L}_{\mathrm{r}}+1\right) \mathrm{f}\left(\mathrm{L}_{\mathrm{r}}\right) \mathrm{f}(1)}{\mathrm{f}\left(\mathrm{L}_{\mathrm{r}}+1\right)}-\mathrm{f}\left(\mathrm{L}_{\mathrm{r}}\right)-\mathrm{L}_{\mathrm{r}} \mathrm{f}(1)\right]
$$

Equation (18) is chosen to bound the numerical results and it can be seen. in Figs. 11 and 12 that the new equation gives conservative estimates.
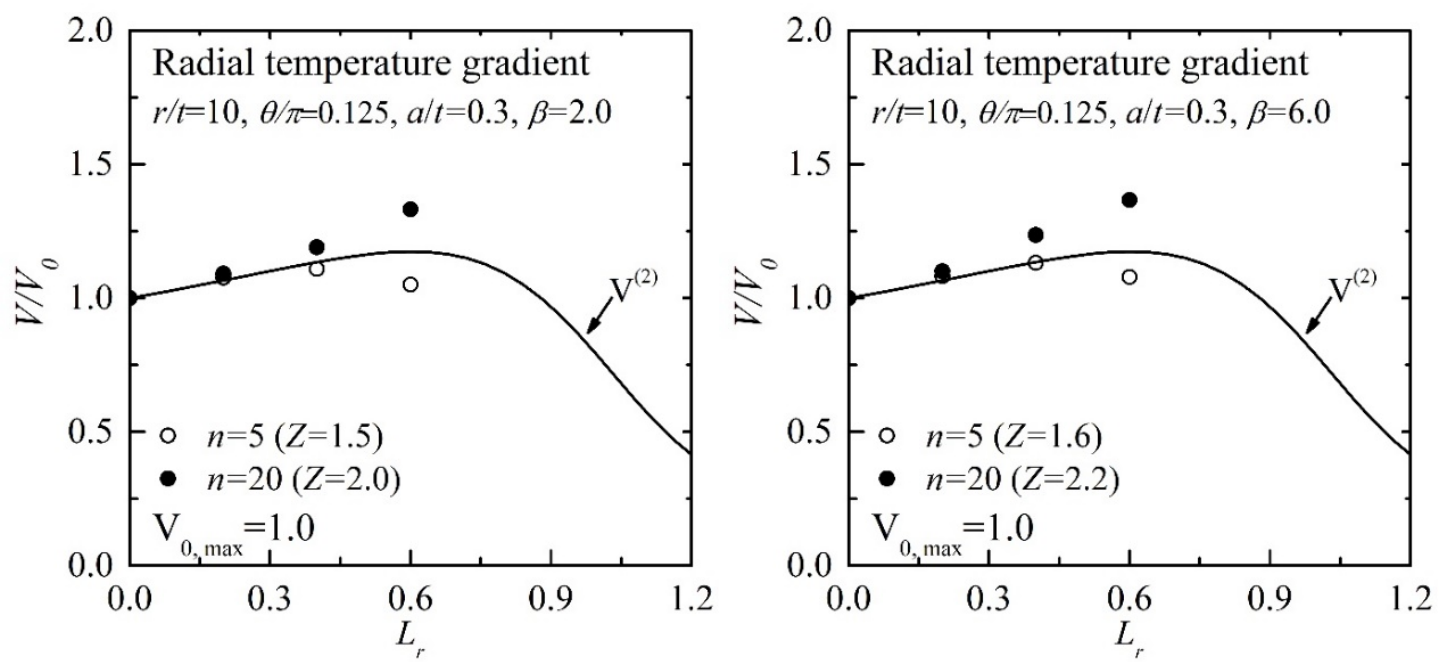

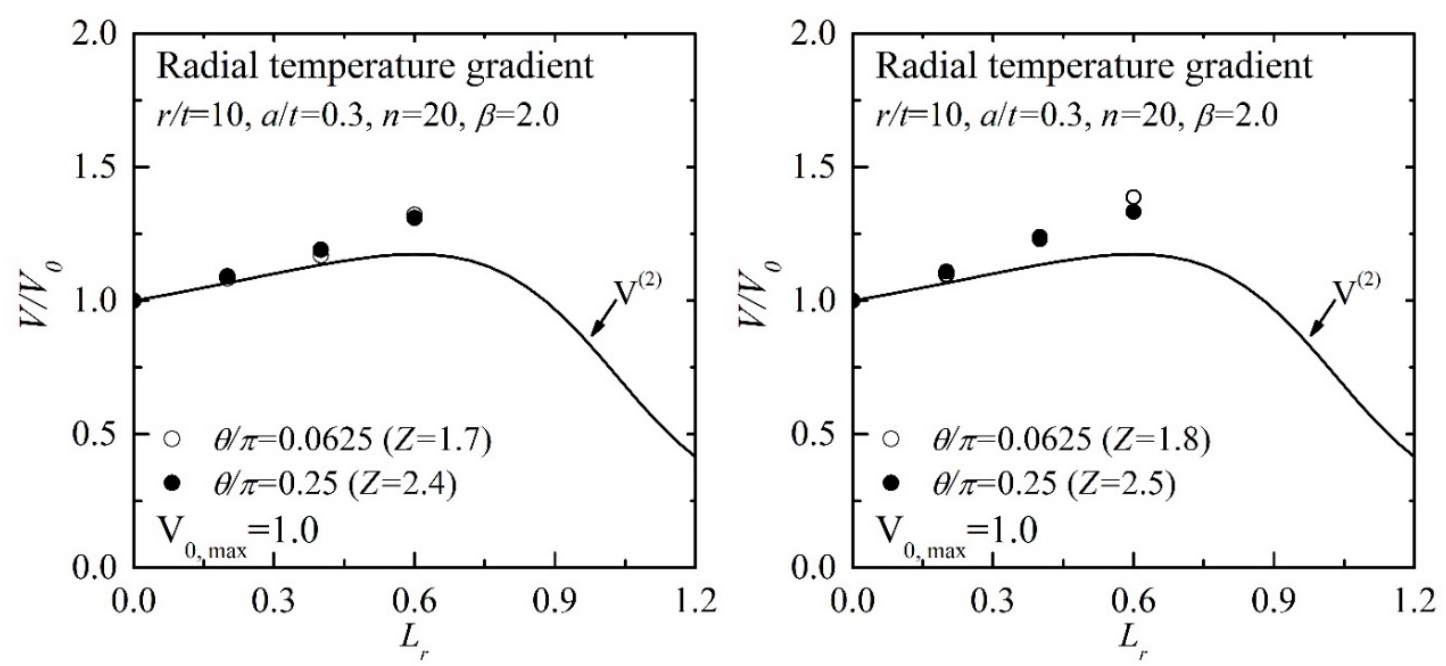

Fig. 10. Comparison of $\mathrm{FE} \mathrm{V} / \mathrm{V}_{\mathrm{o}}$ results with estimated ones for cases of moderate $\mathrm{Z}(<3)$ and $\mathrm{V}_{\mathrm{o}, \max }=1$.
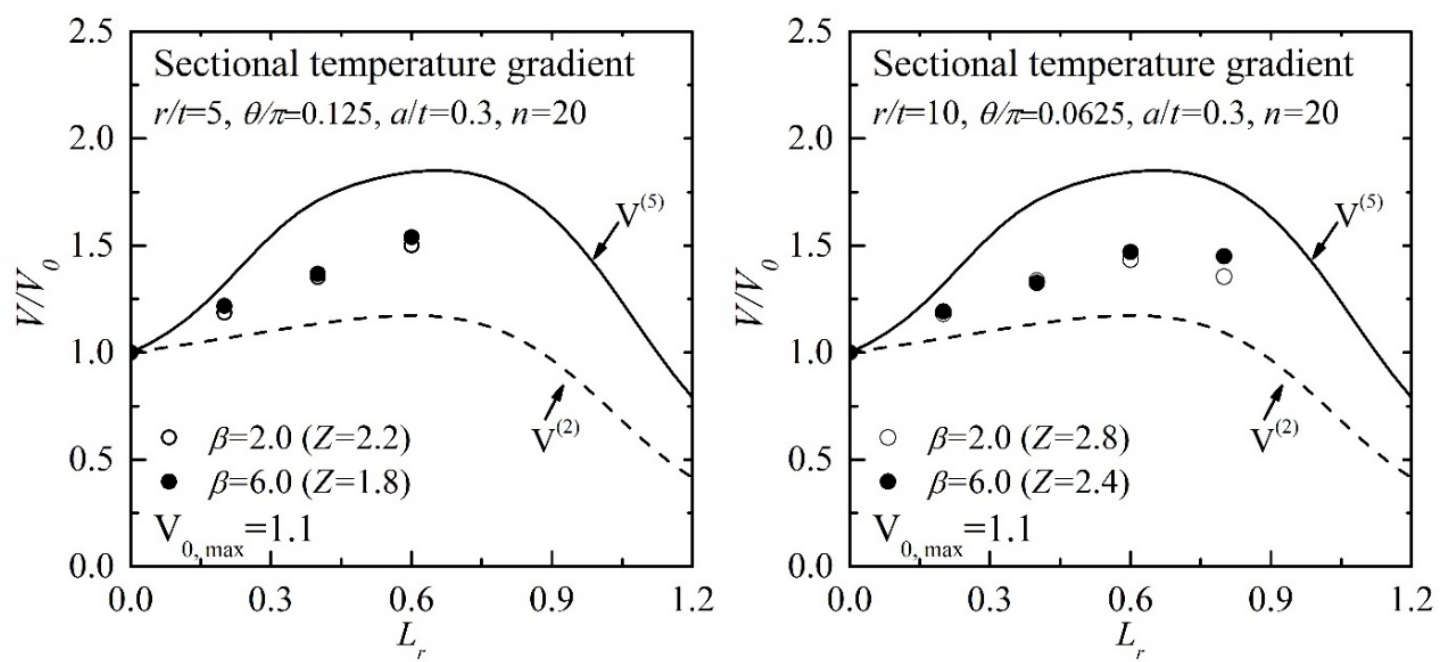

Fig. 11. Comparison of $\mathrm{FE} \mathrm{V} / \mathrm{V}_{\mathrm{o}}$ results with estimated ones for cases of moderate $\mathrm{Z}(<3)$ and $\mathrm{V}_{\mathrm{o}, \max }>1$.
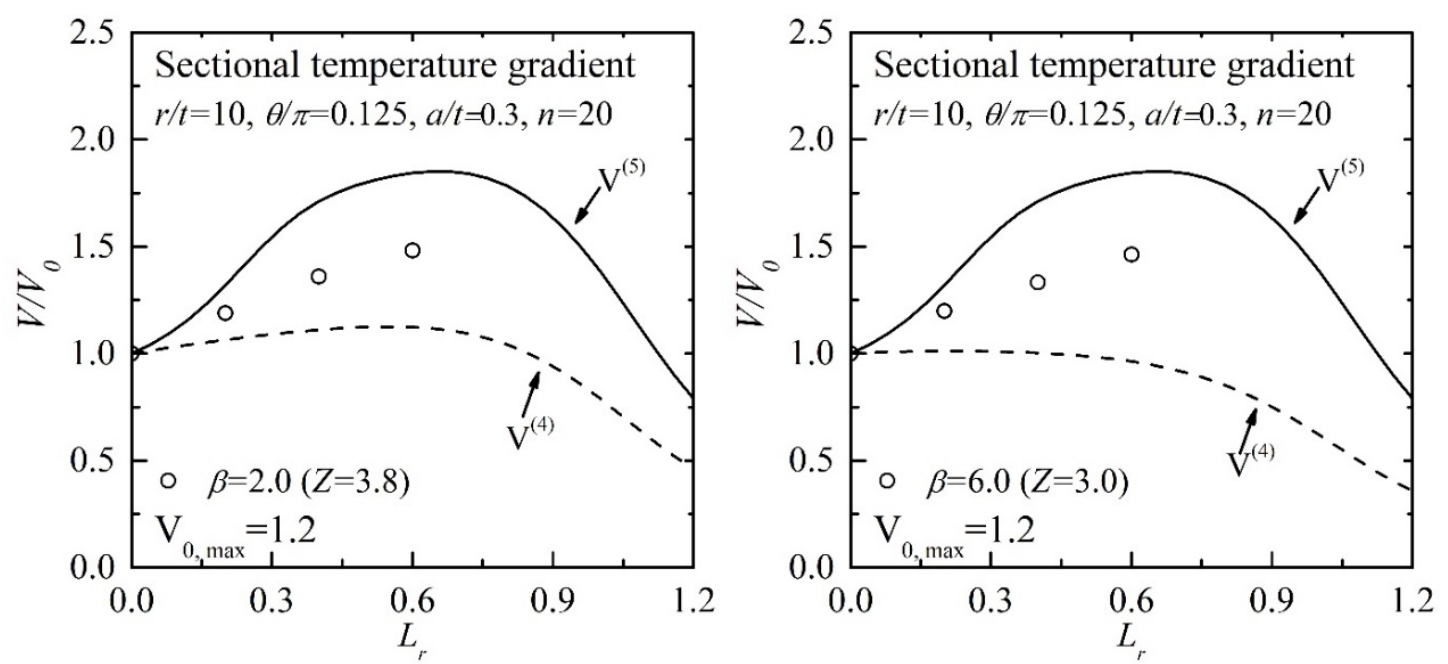

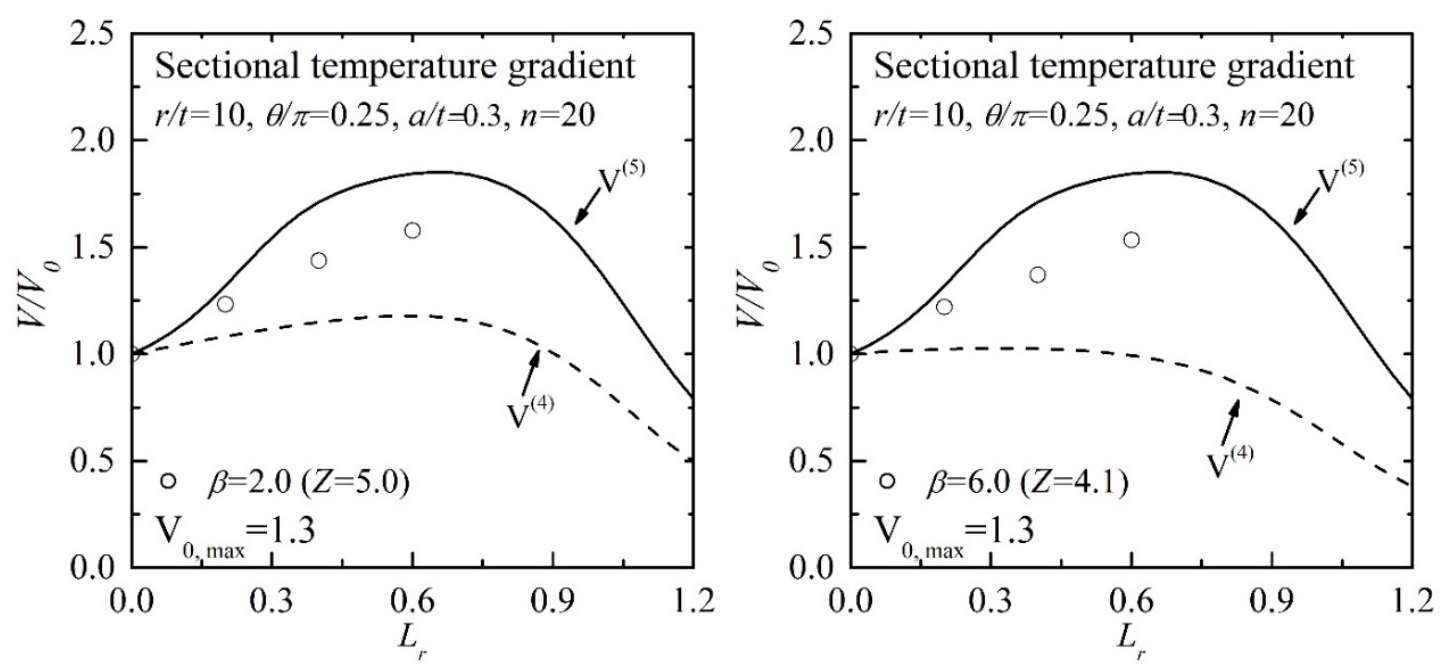

Fig. 12. Comparison of $\mathrm{FE} \mathrm{V/V}$ o results with estimated ones for cases of large $\mathrm{Z}(>3)$ and $\mathrm{V}_{\mathrm{o}, \max }>1$.

\section{RESULTS FOR SMALL SECONDARY LOADING $(\beta \leq 1)$}

For small secondary loads, $\beta<1$, it is difficult to evaluate the degree of elastic follow-up as response is essentially elastic. In the complete absence of plastic strains, a value of $\mathrm{Z}$ cannot be calculated from Eq. (11) and hence selection of a $\mathrm{V}$ estimation equation, $\mathrm{V}^{(2)}$ or $\mathrm{V}^{(4)}$, cannot be made. However, as discussed in Section 5.2.2, the value of $\mathrm{V}_{\mathrm{o} \text {,max }}$ can be an indicator of elastic-plastic response with elastic follow-up regarded as moderate for $\mathrm{V}_{\mathrm{o}, \max }=1$, but potentially large when $\mathrm{V}_{\mathrm{o}, \max }>1$.

Figure 13 shows the $F E$ results for $V / V_{o}$ for $V_{o, \max }=1$, together with the $V$ factor estimation equation, $\mathrm{V}^{(2)}$. Results show that $\mathrm{V}^{(2)}$ reasonably bounds the FE results and thus can be used for practical applications. Thus, the scope of this expression can be extended to cases of small secondary loads for which $\mathrm{V}_{\mathrm{o} \text {, max }}=1$, without determination of $\mathrm{Z}$. This does, however, require the magnitude of the secondary loads to be scaled in order to determine $V_{0}$ for a range of $\beta$ and hence determine $\mathrm{V}_{\mathrm{o} \text {,max }}$. 

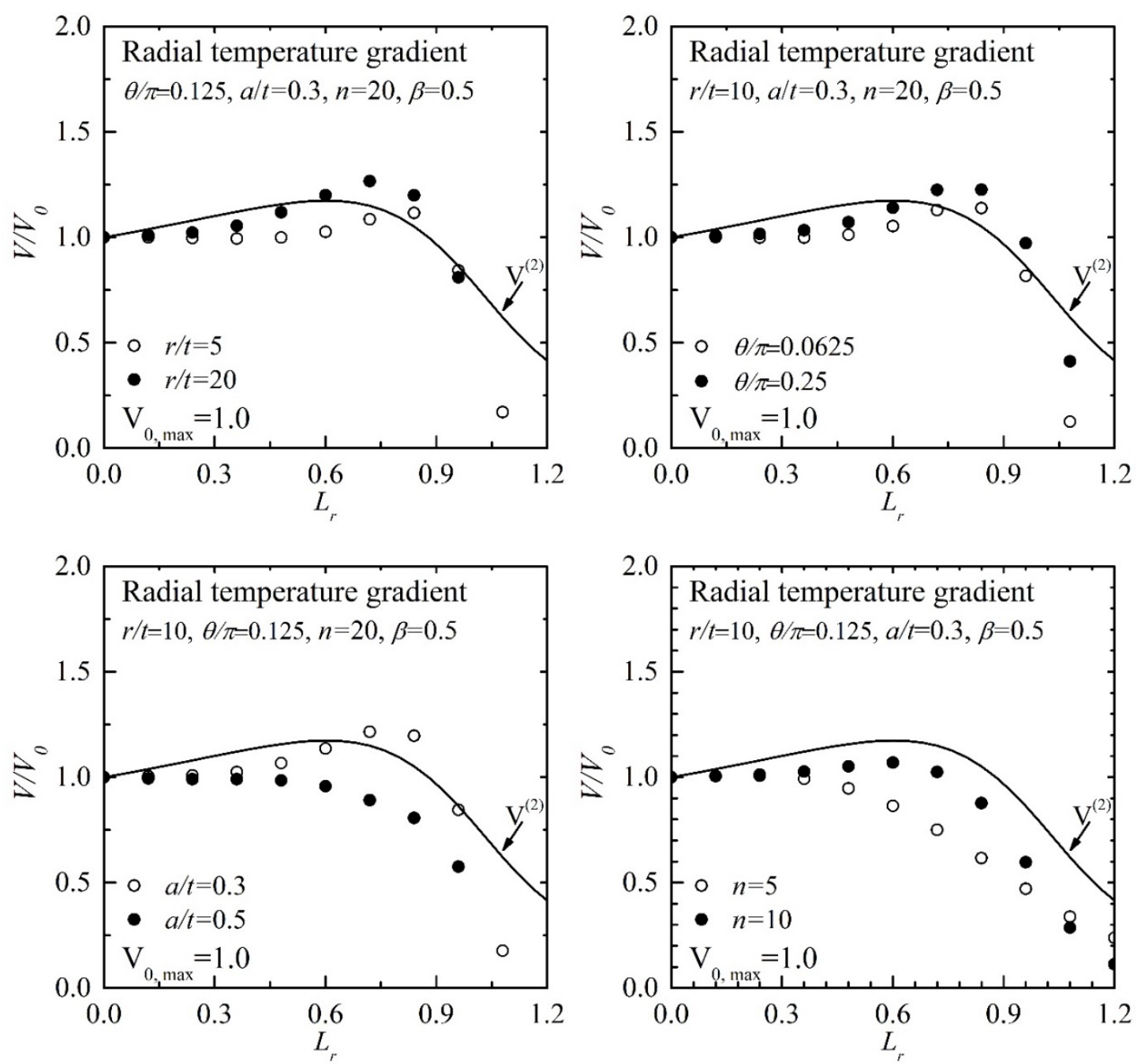

Fig. 13. Comparison of $\mathrm{FE} \mathrm{V/V}$ o results with estimated ones for cases with small $\beta$ $(<1)$ with $\mathrm{V}_{\mathrm{o}, \max }=1.0$.

Figure 14 shows the $\mathrm{FE} \mathrm{V} / \mathrm{V}_{\mathrm{o}}$ results for $\mathrm{V}_{\mathrm{o}, \max }>1$. Much higher values of $\mathrm{V} / \mathrm{V}_{\mathrm{o}}$ are now obtained. As a value of $\mathrm{Z}$ cannot be determined for these cases, $\mathrm{V}^{(4)}$ cannot be used directly. However, it has been found, similar to the results in Section 5.2.2, that Eq. (7) with a fixed value of $Z=3$ provides a reasonable description of behaviour. The corresponding estimation equation is

$$
\mathrm{V}^{(6)} / \mathrm{V}_{\mathrm{o}}=\mathrm{f}\left(\mathrm{L}_{\mathrm{r}}\right)+\frac{1}{3} \mathrm{~h}_{1}\left(\mathrm{~L}_{\mathrm{r}}, \beta\right)
$$

Estimated values of $\mathrm{V} / \mathrm{V}_{\mathrm{o}}$ using this equation are shown in Fig. 14, demonstrating that this new equation gives reasonable estimates of FE response. It should be recognised that the impact of the value of $\mathrm{V}$ on assessments is small for small $\beta$, particularly at larger $\mathrm{L}_{\mathrm{r}}[3]$, and therefore the agreement in Fig. 14 is sufficient for practical applications. 

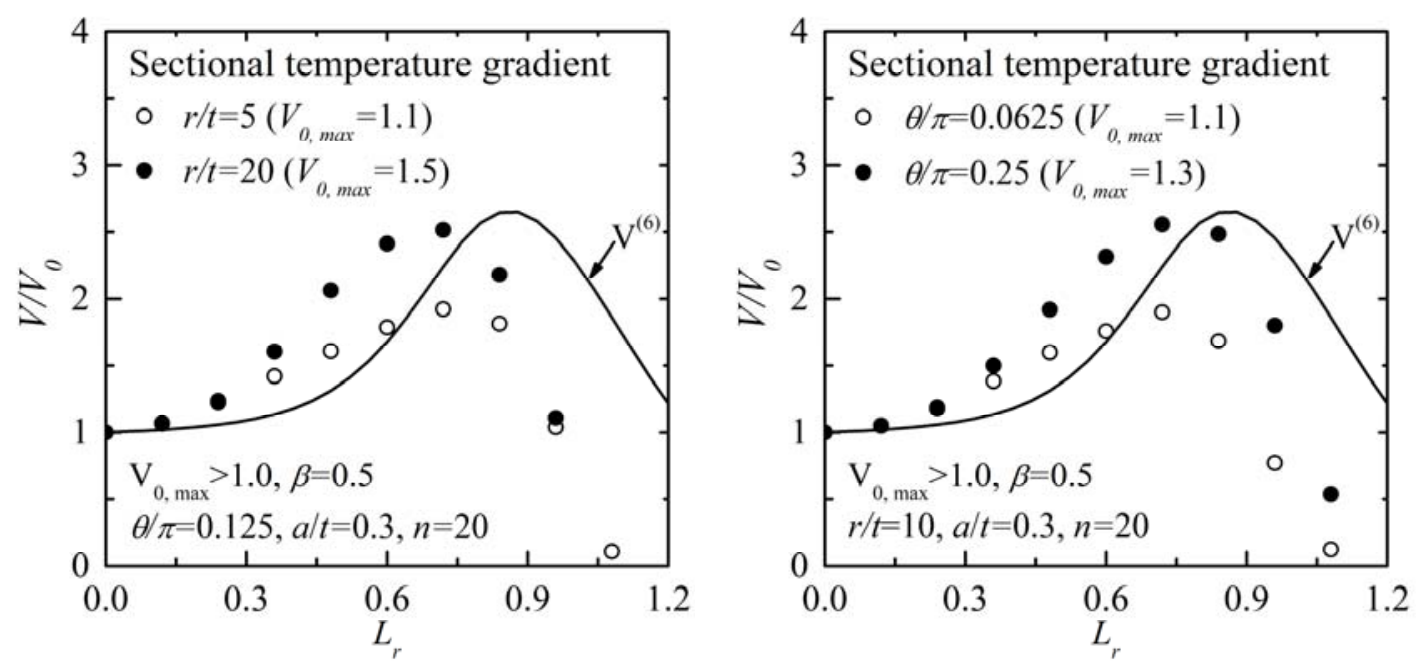

Fig. 14. Comparison of FE V/Vo results with estimated ones for cases of small $\beta(<1)$ with $\mathrm{V}_{\mathrm{o}, \max }>1.0$.

The above proposals for $\beta<1$ are not necessarily continuous with those in Section 5.2 for $\beta>1$. For example, when mechanical loading is applied after thermal loading, $\mathrm{V}^{(4)}$ is used for $\beta>1$ whereas $\mathrm{V}^{(6)}$ is used for $\beta<1$. The estimate of $\mathrm{V}^{(6)}$ is a special case of $\mathrm{V}^{(4)}$ with $\mathrm{Z}=3$ and therefore the proposals are continuous for $\mathrm{Z}=3$ but not otherwise, as illustrated in Fig. 15 which shows the effect of $Z$ on $V^{(4)}$ when $\beta$ is fixed to 1. However, as noted above, it is difficult to estimate the degree of elastic follow-up for small secondary loads and for these cases the impact of the value of $\mathrm{V}$ on assessments is small.

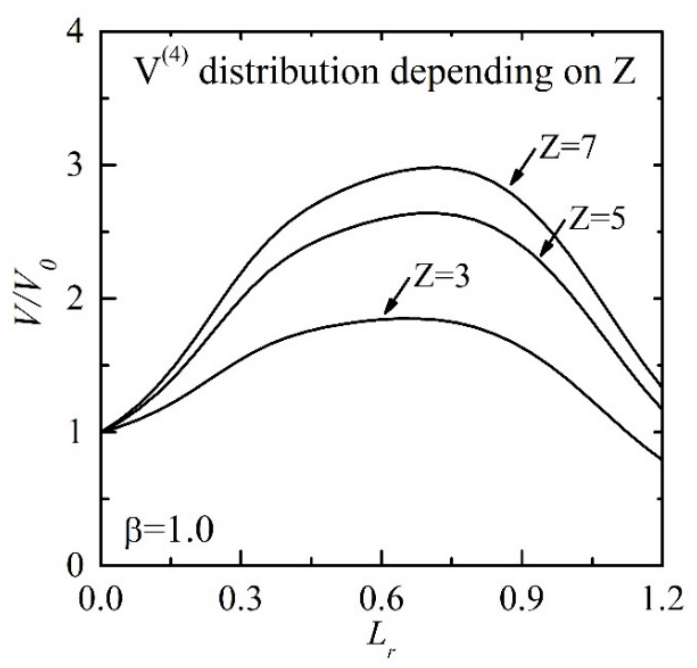

Fig. 15. Variation of $\mathrm{V}^{(4)} / \mathrm{V}_{\mathrm{o}}$ with $\mathrm{Z}$ for $\beta=1$.

\section{CONCLUSIONS}

In this paper, finite element validation of the estimation equations for $\mathrm{J}$ under combined primary and secondary loading via the parameters $\mathrm{V}^{(2)}$ and $\mathrm{V}^{(4)}$, proposed in 
Part 1 [5], has been examined. In the FE analysis, a pipe with a circumferential internal surface crack subject to axial tension and thermal loading has been considered. Relevant parameters affecting $\mathrm{J}$, such as the crack depth and length, the magnitude of thermal loading, relative magnitude of primary and secondary loads, loading sequence and material properties, have been systematically varied. Based on comparisons with detailed FE analysis results, the following conclusions are drawn.

- When mechanical loading is applied after thermal loading with $\beta>1$, the proposed $\mathrm{V}$ estimation equations in [5] can be used; $\mathrm{V}^{(2)}$ for $\mathrm{Z} \leq 3$ and $\mathrm{V}^{(4)}$ for $\mathrm{Z}>3$.

- When thermal loading is applied after mechanical loading with $\beta>1$, the FE results suggest that the proposed $\mathrm{V}$ estimation equations have limited applicability. Based on the FE results, $\mathrm{V}^{(2)}$ can be used for $\mathrm{V}_{\mathrm{o}, \max }=1$ but for $\mathrm{V}_{\mathrm{o}, \max }>1$, a new estimation equation $\mathrm{V}^{(5)}$ is proposed, by modifying $\mathrm{V}^{(4)}$.

- For $\beta \leq 1$, it is found that $\mathrm{V}^{(2)}$ can be used for $\mathrm{V}_{\mathrm{o}, \max }=1$, regardless of the loading sequence. For $\mathrm{V}_{\mathrm{o}, \max }>1$, a new estimation equation $\mathrm{V}^{(6)}$ is proposed, again by modifying $\mathrm{V}^{(4)}$.

\section{ACKNOWLEDGEMENT}

This research was supported by National Research Foundation of Korea (NRF) funded by the Ministry of Science, ICT and Future Planning. (NRF2016M2A8A1952771) 


\section{REFERENCES}

[1] R6 Revision 4, Assessment of the Integrity of Structures Containing Defects, Amendment 11, EDF Energy Nuclear Generation, Gloucester (2015).

[2] Oh C-Y, Kim Y-J, Budden PJ, Ainsworth RA. Biaxial stress effects on estimating $\mathrm{J}$ under combined mechanical and thermal stresses. Int $\mathrm{J}$ Pres Ves Piping 2011;88:365-74.

[3] Ainsworth RA. Consideration of elastic follow-up in the treatment of combined primary and secondary stresses in fracture assessments, Engng Fract Mech 2012;96,558-569.

[4] Song T-K, Oh C-Y, Kim Y-J, Ainsworth RA, Nikbin K. Approximate J estimates for combined primary and secondary stresses with large elastic follow-up, Int J Pres Ves Piping 2013; 111-112, 217-231.

[5] Ainsworth RA, Kim Y-J. Fracture assessments with elastic follow-up for combined primary and secondary loadings. Part 1: Predictive Models, Engng Fract Mech 2019, submitted for publication.

[6] R A Ainsworth, Further analysis of fracture under combined primary and secondary loading with elastic follow-up, EDF Energy Nuclear Generation Report E/REP/BBGB/0126/GEN/14 (2014).

[7] ABAQUS, ABAQUS Standard/User's Manual, Version 6.16, Dassaults Systems Inc, 2016.

[8] Roche RL. Modes of failure - primary and secondary stresses. J Press Vess: T ASME 1988; 110: 234-239.

[9] Je J-H, Kim Y-J, Lee K-H, Jerng D-W. A simple method to estimate elastic follow-up factors for transient creep parameter $\mathrm{C}(\mathrm{t})$ under secondary stress. J Strain Analysis, 2016;51,336-346. 